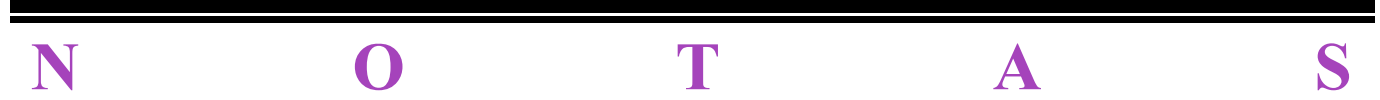




\section{CAUSALIDAD, CONSECUENCIALISMO Y DEONTOLOGISMO}

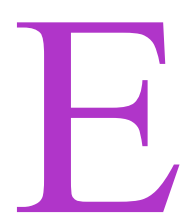

n el número 4 de $D O X A$ Carlos Nino ha presentado un argumento, tan conciso como brillante e incisivo, que en su opinión bastaría para demostrar que el consecuencialismo «no puede ser una teoría moral adecuada» ${ }^{1}$. Por supuesto el consecuencialismo ya ha sido objeto -especialmente en las dos últimas décadasde muchas y muy variadas críticas ${ }^{2}$. Pero la que ahora formula Nino (basada en la idea de que el concepto de «causa» lleva implícitas ciertas presuposiciones normativas y por consiguiente ha de ser manejado con sumo cuidado cuando se le asigna un papel preponderante en la articulación de una teoría moral) representa, si no estoy mal informado, una contribución original que amplía el repertorio convencional de objeciones al consecuencialismo.

En pocas palabras (si es que es posible emplear menos que las que le han bastado al autor), lo que Nino sostiene es lo siguiente: el concepto ordinario de causa, aplicado a acciones humanas, encierra ciertas presuposiciones normativas (provenientes en parte de la moral positiva) que están introducidas en la definición de las «circunstancias normales del contexto» por contraposición a las cuales individualizamos como «causa» alguna de las condiciones (positivas o negativas) necesarias y conjuntamente suficientes para la producción de un resultado; al hacer uso del concepto de causa en el seno de una moral crítica se puede evitar la adhesión inadvertida a la moral positiva bien empleando un concepto de responsabilidad que no dependa del concepto de causa, bien introduciendo un concepto revisado de causa en el que las presuposiciones normativas implícitas provenientes de la moral positiva sean reemplazadas por otras provenientes

${ }^{1}$ Carlos S. Nino, «El cuatrilema del consecuencialismo», en Doxa, 4 (1987), 365-366.

${ }^{2}$ Vid., por todos, la excelente recopilación a cargo de Samuel Scheffler, Consequentialism and its Critics (Oxford; Oxford University Press, 1988). 
De una moral crítica; pero dado que el consecuencialismo «parte de un principio que valora a las acciones exclusivamente por sus efectos causales en el bienestar, utilidad, miseria o dolor de la gente», no dispone de esas posibilidades y se ve enfrentado de hecho al siguiente cuatrilema: o bien hace depender sus conclusiones respecto a qué acciones u omisiones son causas de un resultado del veredicto de la moral positiva, convirtiéndose en esclavo de ella por aberrante que sea; o bien las hace depender de normas de deber de una moral crítica, con lo que se transformaría en un sistema deontológico; o bien las hace depender de deberes surgidos del propio principio consecuencialista, con lo que resultaría circular; o bien, finalmente, considera como causa cualquier condición necesaria (es decir, estipula un concepto de causa del que estaría ausente la cláusula restrictiva «en las condiciones normales del contexto», con lo que quedaría liberado de presuposiciones normativas), lo que tendría consecuencias altamente contraintuitivas.

En este artículo intentaré demostrar que el consecuencialismo puede escapar al cuatrilema en el que nino lo encierra. Como es obvio, ello no equivale a defender la tesis más fuerte de que el consecuencialismo es «una teoría moral adecuada» (o, como yo preferiría decir, una estructura adecuada para una teoría moral aceptable): equivale tan sólo a afirmar que si no lo es -cuestión sobre la que aquí no pretendo pronunciarme-, habrá de ser por alguna razón distinta de la esgrimida por nino en esta ocasión.

La argumentación de nino reposa sobre dos premisas: una cierta definición de «consecuencialismo» y una determinada explicación de la idea de «causa». Por consiguiente sus conclusiones pueden ser esquivadas poniendo en tela de juicio alguna de las dos o ambas. Respecto a la primera de esas dos premisas, me parece en efecto que nino ha manejado una noción de «consecuencialismo» indebidamente estrecha: una noción, diría yo, que casi acaba resultando extensionalmente equivalente a la de «utilitarismo» ${ }^{3}$. Hay un dato que me parece significativo: cuando en algunos trabajos anteriores nino presentó tentativamente el argumento que ahora desarrolla en profundidad, vio en él la base

${ }^{3}$ Para ser más riguroso, diría que acaba resultando extensionalmente equivalente a lo que Amartya Sen ha denominado «welfarism» (término para el que, sinceramente, no me siento capaz de proponer un equivalente castellano presentable); más adelante me referiré a la diferencia entre esta noción y la de utilitarismo; vid. Amartya K. Sen, «Utilitarianism and Welfarism», en Journal of Philosophy, 76 (1979), 463-489. 
para una objeción que afectaba precisamente al utilitarismo ${ }^{4}$; ahora el blanco del argumento se ensancha y ya no es sólo esa forma particular de consecuencialismo a la que llamamos «utilitarismo», sino cualquier clase de consecuencialismo. Pero es evidente que los defectos del utilitarismo en particular no pueden ser considerados automáticamente como vicios del consecuencialismo en general: ese salto puede darse si se demuestra que afectan a aquellos rasgos que el utilitarismo comparte con cualquier otra forma de consecuencialismo y que precisamente hacen de él una de las variantes de éste; pero no si afectan a sus rasgos o elementos específicos, a aquellos que definen su identidad particular y que como tales no formarán parte de otras teorías morales no utilitaristas pero igualmente consecuencialistas.

El gran problema, llegados a este punto, consiste evidentemente en precisar qué es lo que podemos considerar como «estructura mínima del consecuencialismo». El término «consecuencialismo», hasta donde yo sé, fue introducido en el discurso filosófico por Anscombe hace apenas tres décadas y no precisamente con unos perfiles nítidamente definidos $^{5}$. Se supone que alude a una familia de teorías morales -o a un tipo de estructura compartida por diferentes teorías morales- de las que, con gran diferencia, el utilitarismo ha sido la más explorada y discutida.

${ }^{4}$ Cfr. Introducción a la Filosofía de la Acción Humana (Buenos Aires; Eudeba, 1987), pág. 98: «Este carácter normativo de la causación por omisión [...] pone en aprietos al utilitarismo...» (la cursiva es mía); Ética y Derechos Humanos (Buenos Aires, Paidós, 1984), pág. 207: «Creo que este enfoque de la causalidad puede poner en serias dificultades al utilitarismo...» (la cursiva es mía). Ciertamente Nino añade pocas líneas después: «Esto podría servir de apoyo a una ética deontológica [...] en lugar de una ética teleológica del tipo utilitarista.» Creo que este último inciso merece dos comentarios: 1) si lo que fracasa es el utilitarismo, ello no constituye por sí solo un argumento decisivo en favor del deontologismo, ya que cabe la posibilidad de que resulten inmunes a la crítica otras formas (no utilitaristas) de consecuencialismo; 2) al hablar de «una ética teleológica del tipo utilitarista» no queda claro si Nino piensa que la crítica afecta a ese tipo especial de «ética teleológica» que sería el utilitarismo, o a las «éticas teleológicas» en general, de las que el utilitarismo sería un ejemplo. Nótese, por otra parte, que la crítica a «una ética teleológica del tipo utilitarista» aparece ahora como crítica al consecuencialismo; y, aunque en último término la cuestión dependa de estipulaciones verbales, el empleo de «teleológico» y «consecuencialista» como términos intercambiables no está exento de dificultades; cfr. John Finnis, Fundamentals of Ethics (Oxford, Clarendon Press, 1983), págs. 84-85.

${ }^{5}$ Cfr. Gertrude E. M. Anscombe, «Modern Moral Philosophy», en Philosophy, 33 (1958) [ahora en Anscombe, Ethics, Religions and Politics, Collected Philosophical Papers, vol. III(Oxford, Basil Blackwell, 1981), págs. 26-42; vid. pág. 36]. 
Ello ha generado una estrecha asociación histórica entre consecuencialismo y utilitarismo, de modo que no resulta fácil determinar qué es lo propio del genus y qué lo diferenciador de la species. O dicho con otras palabras: no es fácil precisar qué rasgos del utilitarismo (como punto de partida mejor conocido) pueden ir siendo desechados y reemplazados por otros de manera que la teoría moral resultante siga siendo aún consecuencialista. El riesgo, evidentemente, consiste en ir adelgazando la connotación del término «consecuencialismo» (mediante restricciones ad hoc diseñadas para ir soslayando las críticas formuladas por los no consecuencialistas) hasta convertirlo en una etiqueta desdibujada bajo la cual quepa prácticamente todo. Ni que decir tiene que con el término «deontologismo» puede forzarse un proceso parecido. Para evitar disputas meramente verbales lo que habrá que ver, en definitiva, es si se puede o no identificar un conjunto de rasgos mínimos definitorios de uno y otro tal que constituyan dos núcleos mutuamente excluyentes y expresivos de alguna diferencia no sólo irreductible, sino importante o significativa.

La exploración de estructuras consecuencialistas no utilitaristas, en cualquier caso, me parece importante para apreciar correctamente el alcance del argumento de Nino. En mi opinión, cualquier forma de consecuencialismo -utilitarismo incluido- puede escapar al cuatrilema. Pero incluso si eso no fuera cierto, mi error podría ser aún un error parcial (exactamente el reverso del que sería en ese caso error igualmente parcial de Nino): porque podría suceder que sólo el utilitarismo -y no otras formas complejas o refinadas de consecuencialismo- quedara efectivamente atrapado en él. Con todo, esa objeción más limitada al argumento de Nino no carecería de importancia: porque sólo el «cuatrilema del consecuencialismo», y no el más modesto «cuatrilema del utilitarismo» que emergería de ese análisis, puede ser visto como un argumento concluyente en favor del deontologismo (que, si no me equivoco, es lo que anda buscando Nino).

La segunda premisa de la que depende la argumentación de Nino consiste en una cierta explicación de la noción de «causa». Sea cual sea la posición que uno adopte respecto a su definición de «consecuencialismo», es posible rechazar sus conclusiones si no se comparte la tesis del carácter (parcialmente) normativo de los enunciados causales típicos del lenguaje ordinario. Francisco Laporta, por ejemplo, la ha criticado en las páginas de esta misma revista ${ }^{6}$. Me inclino a pensar, por el contrario, que las

${ }^{6}$ Francisco J. Laporta, «Algunos problemas de los deberes positivos generales 
tesis de Nino respecto a la inclusión de presupuestos normativos entre los elementos presentes en la atribución de un resultado a un individuo como efecto de su acción u omisión son básicamente correctas. Lo que dudo, sin embargo, es que de ahí se derive problema alguno para el consecuencialismo (en cualquiera de sus formas). La confusión provendría a mi juicio de haber tratado como si fuesen una sola dos cuestiones diferentes: qué es lo que hace que una acción o una omisión sean causalmente eficaces y qué lo que determina que puedan ser individualizadas -en contextos atributivos- como la causa de un cierto estado de cosas (que se presenta entonces como $s u$ resultado).

Dividiré mi exposición en tres apartados. El objeto de los dos primeros seguramente ya habrá quedado claro: investigar la estructura del consecuencialismo y la de la idea de causa. Pero la discusión puede prolongarse además -en un tercer apartado- retorsivamente: porque, si no me equivoco, el deontologismo sí que encuentra algunas dificultades serias en relación con la idea de causa. Y para salir de ellas tiene que admitir ciertas modificaciones que acaban convirtiéndolo en algo muy parecido a las versiones complejas o refinadas del consecuencialismo que me propongo explorar. Todo lo cual avalaría la intuición -que aquí es imposible desarrollar y que presento meramente como eso: como una intuición-, adelantada en diferentes formas por autores tan distintos entre sí en varios sentidos como Mackie, Scanlon, Sen, Scheffler, Parfit o Nozick, de que lo que hay que buscar no es tanto el argumento definitivo que dé la victoria al deontologismo sobre el consecuencialismo o a la inversa, sino más bien algún tipo de estructura que combine o unifique en un nivel superior de abstracción los rasgos más atractivos de cada uno de ellos?

(observaciones a un artículo de Ernesto Garzón Valdés)», en Doxa, 3 (1986), 55-63; vid. especialmente, págs. 59 y sigs.

${ }^{7}$ Cfr. John Mackie, Ethics, Inventing Right and Wrong (Harmondsworth; Penguin, 1977), cap. 7, especialmente págs. 149-150 y 167-168; T. M. Scanlon, «Rights, Goals and Fairness», en Erkenntnis, 2 (1977), 81-95 [ahora en Scheffler (ed.), Consequentialism and its Critics, cit. en nota 2, págs. 74-92, por donde se cita], que habla de una «tercera vía» (pág. 81); Samuel Scheffler, The Rejection of Consequentialism. A Philosophical Investigation of the Considerations Underlying Rival Moral Conceptions (Oxford; Clarendon Press, 1982), que califica su propuesta como «híbrida» (pág. 5); Amartya K. Sen, «Rights and Agency», en Philosophy and Public Affairs, 11 (1982), 3-39 [ahora en Scheffler (ed.), Consequentialism and its Critics, cit., págs. 187-223, por donde se cita]; Derek Parfit, Reasons and Persons (Oxford; Clarendon Press, 1984), que aboga por una «teoría unificada» (pág. 112). La inclusión de Nozick en 


\section{La estructura mínima del consecuencialismo}

Si hemos de hacer caso a Rawls, la estructura de una teoría moral está determinada en gran parte por la forma en que define y conecta las dos nociones básicas de lo «bueno» y lo «correcto». Desde ese punto de vista, se suelen destacar dos rasgos mínimos como definitorios del consecuencialismo: que atribuye prioridad lógica a lo bueno, ya que concebiría lo correcto como la maximización de lo bueno; y que sólo considera portadores de valor intrínseco a los «estados de cosas», de manera que todo lo demás (acciones, reglas, motivos o disposiciones...) sólo tendrían valor en la medida en que conduzca a estados de cosas valiosos. Cualquier teoría moral consecuencialista -aceptando provisionalmente esta caracterización- operaría entonces del siguiente modo: especificaría en primer lugar qué es lo que confiere valor a un estado de cosas, qué es lo que determina su mayor o menor bondad; a la luz de ese criterio, jerarquizaría de mejor a peor todos los estados de cosas posibles; y calificaría como correcta a la acción (o regla, disposición, etc.) que conduzca al mejor de los estados de cosas que el agente esté en condiciones de producir. Pero esta es sin duda una descripción sumaria que debe ser matizada en muchos de sus extremos. En particular, creo que deben analizarse con más calma tres puntos relativos a la apreciación del valor de los estados de cosas; y tres más que se refieren a la forma en que se pasa de los juicios acerca de la bondad de esos estados a los juicios sobre la corrección de las acciones.

i) Por lo que hace a la apreciación del valor de los estados de cosas no creo que haga falta insistir, en primer lugar, en que dentro del marco genérico del consecuencialismo podemos obtener múltiples teorías morales diferentes según el principio o principios que cada una use para definir qué es lo que hace bueno a un estado de cosas: en este sentido el utilitarismo no representa más que una posibilidad entre otras muchas (y, por cierto,

esta relación puede desconcertar a quienes sólo tengan en mente Anarchy, State and Utopia (Nueva York, Basic Books, 1974) [hay trad. cast. de R. Tamayo, Anarquía, Estado y Utopía (México, F.C.E., 1988)], donde propugna sin ambages una posición deontologista (a pesar de la pequeña cuña que desliza al final de la nota de las págs. 29-30 [trad. cast., págs. 41-42]) y se perfila como uno de los más duros críticos del consecuencialismo; pero no para quien recuerde lo escrito más tarde por él en sus Philosophical Explanations (Cambridge, Mass., Harvard University Press, 1981), págs. 494-498, donde, aun manifestando su «obvia inclinación» hacia el deontologismo (pág. 498), se esfuerza en explorar las vías para una posible unificación (hablando, por cierto, de «teleologismo» y no de «consecuencialismo»). 
no la más prometedora, aunque desde luego sí la más conocida y discutida).

Ahora bien, las distintas teorías morales que comparten una estructura consecuencialista pueden diferir entre sí en otros extremos. Un segundo aspecto que puede marcar la diferencia tiene que ver no con el principio o principios que definen qué estados de cosas son buenos, sino con el sentido que cada una dé a la idea misma de «estado de cosas»: en particular, se puede o no considerar a la acción productora como parte del estado de cosas producido. Para muchos esa inclusión representaría en realidad la salida pura y simple del marco consecuencialista, ya que hablar del «hacer del agente que actúa» como parte de «lo hecho» no pasaría de ser un abuso verbal. No creo, de todos modos, que esa posibilidad deba ser descartada de antemano: lo que habrá que ver en cualquier caso es si el tipo de estructura moral que resultaría de admitir esa inclusión puede aún ser diferenciada -en algún sentido no trivial- de los que señalamos usualmente como casos típicos de deontologismo.

Las mismas dudas, o quizá más severas, rodean a un tercer aspecto en el que las teorías morales consecuencialistas pueden diferir entre sí (y que si no me equivoco está estrechamente ligado al anterior). Empleando términos puestos en circulación por Nagel y Parfit, suele darse por supuesto que el consecuencialismo -en cualquiera de sus formas- sólo genera razones morales «neutrales respecto al agente» ${ }^{8}$ : lo que eso quiere decir es que los estados de cosas son mejores o peores desde una perspectiva impersonal, que su valoración no puede arrojar resultados diferentes para distintas personas (que utilizan como patrón de esa evaluación la misma teoría moral) según cuál sea la posición o el papel que corresponda a cada una de ellas en dicho estado. Ese rasgo puede ser valorado como una ventaja o como un inconveniente: pero en lo que sí suele haber acuerdo es en que dentro del consecuencialismo no hay sitio para ninguna clase de razones morales «relativas al agente» (es decir, que un mismo estado de cosas no puede tener un valor para quien ocupa en él una determinada posición o papel que sea distinto del que tenga para cualquier otro fuera de esas posiciones o papeles). Esa conclusión,

${ }^{8}$ Cfr. Thomas Nagel, «The Limits ofObjectivity», en S. McMurrin(ed.), The Tanner Lectures on Human Values, vol. I (Salt Lake City, Utah University Press; Nueva York/Cambridge, Cambridge University Press, 1980), págs. 77-139, págs. 101-103; Id., The View from Nowhere (Nueva York/Oxford; Oxford University Press, 1986), págs. 152-153; Derek Parfit, Reasons and Persons, cit., pág. 143. 
no obstante, depende como es obvio de la extensión que estemos dispuestos a reconocer para el término «consecuencialismo»: y creo, nuevamente, que la directriz a seguir para acoger o no esta posibilidad radica en preguntarnos si acogiéndola obtendríamos algo diferenciable aún de los casos centrales o típicos de deontologismo. Si la respuesta fuese afirmativa podríamos distinguir entre aquellas formas de consecuencialismo en las que tiene cabida una valoración de los estados de cosas relativa al agente y aquellas otras en las que semejante posibilidad queda excluida.

ii) Un segundo bloque de cuestiones es el que tiene que ver con la traslación de los juicios sobre la bondad de los estados de cosas a los juicios sobre la corrección de las acciones. Dentro de él, una primera posibilidad de diferenciación entre teorías morales consecuencialistas estriba en si conciben lo correcto precisamente como maximización o simplemente como alguna clase de función -no necesariamente maximizadora- de lo bueno? El punto de vista más extendido exige la maximización. Ahora bien, aunque la prioridad lógica de lo bueno sobre lo correcto requiere sin duda que lo segundo sea una variable dependiente de lo primero, que la relación entre ambas dimensiones haya de venir definida justamente como maximización parece, en principio, sólo una posibilidad entre otras. Me parece que en el fondo esta cuestión tiene mucho que ver -pero de ello me ocuparé más tarde- con el tipo de definición de lo bueno que cada teoría moral consecuencialista haga suya (y, más concretamente, con el dato diferenciador de si su concepción de lo bueno es monista o pluralista).

Los dos aspectos restantes en relación con los cuales pueden perfilarse distintas variantes dentro del consecuencialismo remiten a cuestiones bastante más trilladas y sólo los mencionaré brevemente. Uno de ellos tiene que ver con el modo en que se forman los juicios acerca de la corrección de las acciones, que puede ser directo o indirecto: en el primer caso la acción correcta sería la que conduzca a estados de cosas buenos (o máximamente buenos); en el segundo, la que derivaría del seguimiento

${ }^{9}$ Frente al punto de vista dominante, que exige la maximización, la idea de que todo lo que necesita el consecuencialismo es definir lo correcto como una función (no necesariamente maximizadora) de lo bueno ha sido sugerida recientemente por Michael Slote, Common-Sense Morality and Utilitarianism (Boston/Londres; Rotuledge \& Kegan Paul, 1985), caps. 3 y 5. Para una crítica de esa idea, vid. Philip Pettit, «Slote on Consequentialism», en Philosophical Quarterly, 36 (1986), 399-412, págs. 401-404. 
de reglas o de la adopción de motivos o disposiciones de conducta cuya aceptación (por parte del individuo o de todos, lo que dibuja a su vez otra posibilidad de diferenciación ${ }^{10}$ ) conduciría a estados de cosas (¿máximamente?) buenos ${ }^{11}$.

Finalmente, las diferentes teorías consecuencialistas pueden hacer suyos muy distintos criterios de adscripción de responsabilidad. Una vez sentado qué estados de cosas son buenos (sea cual sea el principio que los define como buenos y la forma en que se conciba la idea misma de «estado de cosas»; y tanto si se da cabida a la relatividad respecto al agente como si no) y, a partir de esa determinación, qué acciones son correctas (exigiendo o no la maximización; estableciéndolo directa o indirectamente), la adscripción de responsabilidad -en un sentido amplio, que cubre la alabanza y el reproche- por la realización u omisión de esas acciones puede o no conferir relevancia a la distinción entre lo que es bueno o correcto con arreglo a la teoría y lo que el agente -usando esa teoría como patrón de evaluación, pero con un conocimiento incompleto o erróneo- juzgó como tal. En ese sentido una teoría consecuencialista no tiene por qué considerar moralmente reprochable cualquier distanciamiento entre la acción que ella misma identifica como correcta y aquella que el agente realiza. Y, si no lo hace, no por ello se convierte inadvertidamente en una posición deontologista: porque el criterio

${ }^{10}$ Sobre la diferencia entre «consecuencialismo individual» $\mathrm{y}$ «consecuencialismo colectivo», vid. Parfit, Reasons and Persons, cit. págs. 30-31.

${ }^{11}$ En este orden de cosas la distinción más discutida -hasta la saciedad- es sin duda alguna la que opone el utilitarismo de actos al utilitarismo de reglas (discusión que incluye, como es de sobra conocido, la cuestión de si uno y otro son o no en realidad extensionalmente equivalentes). Sobre el también bastante transitado «utilitarismo de motivos», vid. Robert M. Adams, «Motive Utilitarianism», en Journal of Philosophy, 73 (1976), 467-481. Pero lo que aquí me interesa destacar es que toda esa gama de posibilidades no queda abierta sólo para el utilitarismo, sino para cualquier clase de consecuencialismo. Entre estas formas indirectas de determinación de la acción correcta por parte de una teoría consecuencialista, resulta sumamente espinosa la cuestión de si cabría pensar incluso en la adopción, por razones consecuencialistas, de una disposición a actuar sobre la base de razones no consecuencialistas (y de si el agregado resultante podría ser aún presentado con sentido como una forma de consecuencialismo); no descarta esa posibilidad D. Parfit, Reasons and Persons, cit. págs. 40 y sigs.; en este sentido contrario, vid. Bernard Williams, «A Critique of Utilitarianism», sec. 6, en J. J. C. Smart y B. Williams, Utilitarianism: For and Against (Cambridge, Cambridge University Press, 1973) [trad. cast. de J. Rodríguez Marín, Utilitarismo: Pro y Contra (Madrid, Tecnos, 1981)]; Id., Ethics and the Limits of Philosophy (Londres, Fontana-Collins, 1985), págs. 107-108; y Michael Stocker, «The Schizophrenia of Modern Moral Theories», en Journal of Philosophy, 73 (1976), 453-466. 
mismo de adscripción de responsabilidad es susceptible a su vez de justificación consecuencialista.

iii) El primero de estos seis puntos -qué es lo que define como «bueno» a un estado de cosas- es, a mi juicio, el que marca las diferencias más radicales entre distintas formas de consecuencialismo. Para trazar un mapa de las diversas posibilidades que quedan abiertas en este terreno puede ser de interés seguir el análisis que nos propone Amartya $\mathrm{Sen}^{12}$. La estrategia de ese análisis consiste en partir del utilitarismo (como variedad más difundida) e ir determinando cómo serían las estructuras morales que resultarían de ir abandonando y reemplazando por otros cada uno de los elementos constitutivos en los que puede descomponerse la concepción utilitarista de lo bueno.

Sea cual sea la forma en que se interprete la noción de «utilidad»-como felicidad, placer, satisfacción de preferencias de cualquier clase o sólo de un cierto tipo, etc.-, todas las formas de utilitarismo conciben la bondad de un estado de cosas como la suma de las utilidades individuales presentes en él. Ello da pie para distinguir dos componentes que, asociados, integran la concepción utilitarista de lo bueno: por un lado, la idea de que para valorar un estado de cosas sólo es relevante la información relativa a qué utilidades individuales están presentes en él («welfarism»); por otro, la tesis según la cual el valor de un estado de cosas viene dado por la suma de las utilidades presentes en él («sum-ranking» o «aditivismo»), de manera que si dos estados de cosas registran la misma cantidad total de utilidad para un conjunto dado de individuos no hay ninguna base para concluir que uno de los dos es mejor que otro (sea cual sea la distribución de la utilidad en cada uno) ${ }^{13}$.

Ahora bien, es posible concebir estructuras consecuencialistas que salgan fuera del espacio utilitarista en la medida en que abandonen en su definición de qué es lo que determina la bondad de un estado de cosas alguno de esos dos elementos o ambos. Entre los teóricos de la economía del bienestar se han construido propuestas basadas en la conservación del primero y el abandono del segundo, que sería reemplazado por un criterio de tipo distributivo, lo que permitiría articular funciones no lineales de bienestar social ${ }^{14}$. Esas propuestas han de hacer frente a un

${ }^{12}$ En «Utilitarianism and Welfarism», cit. [vid., supra, nota 3].

${ }^{13}$ Loc. cit. pág. 468.

${ }^{14}$ Cfr. P. J. Hammond, «Equity, Arrow's Conditions and Rawls' Difference Principle», en Econometrica, 44 (1976), 793-804; S. Strasnick, «The Problem of Social Choice; Arrow to Rawls», en Philosophy and Public Affairs, 5 
buen número de problemas de gran complejidad técnica que en este momento no viene al caso examinar ${ }^{15}$. Lo que sí me interesa subrayar, de todos modos, es que las consideraciones distributivas se integran en la estructura resultante precisamente como un elemento de la definición de la bondad para los estados de cosas: es decir, este tipo de estructuras consecuencialistas define como buenos aquellos estados de cosas en los que la utilidad está distribuida de un cierto modo (p. ej., en los que es más alta la utilidad del individuo peor situado, como estipula el «principio leximin» ${ }^{16}$ ), no aquellos en los que la suma de utilidades es mayor; y al hacerlo se diferencia tanto del utilitarismo como de las estructuras morales no consecuencialistas, en las que la importancia de los criterios distributivos no se insertaría en la definición misma de lo bueno, sino que aparecería de la mano de lo «correcto», esto es, como una restricción a la persecución de lo bueno. Quizá pueda pensarse que lo que hemos alcanzado por esta vía no es en realidad sino deontologismo embozado bajo el ropaje verbal del consecuencialismo ${ }^{17}$. No examinaré esa cuestión

(1976), 241-273; Id., «Social Choice and the Derivation of Rawls’ Difference Principle», en Journal of Philosophy, 73 (1976), 85-99; C. D’Aspremont y L. Gevers, «Equity and Informational Basis of Collective Choice», en Review of Economic Studies, 46 (1977), 199-210; R. Deschamps y L. Gevers, «Leximin and Utilitarian Rules: A Joint Characterization», en Journal of Economic Theory, 17 (1978), 143-163.

${ }^{15}$ Piénsese, p. ej., que la cuestión de determinar de qué maneras es posible agregar utilidades individuales ( $\mathrm{y}$, en concreto, de si cabe o no una agregación no aditiva, de si son viables o no funciones no lineales de bienestar social) depende de la respuesta que demos a la pregunta previa acerca de los modos en que sea posible medirlas y compararlas (medición cardinal, escalas ordinales con o sin medidas de intervalo, etc.). Para un tratamiento global de estos problemas, vid. James Griffin, Well-Being, Its Meaning, Measurement and Moral Importance (Oxford: Clarendon Press, 1986), caps. VI y VII.

${ }^{16}$ Para una síntesis clara y accesible del significado y las dificultades del «principio leximin» [lexical maximin], vid. Damián Salcedo Megales, «La fundamentación normativa de un principio igualitarista», en Anuario de Filosofía del Derecho, nueva época, 4 (1987), 193-218.

${ }^{17}$ Rawls ha sostenido que «si la distribución de los bienes se cuenta también como un bien, quizá de orden superior, y la teoría nos dirige hacia la producción del mayor bien (incluyendo el bien de la distribución entre otros), lo que tenemos ya no es un punto de vista teleológico en el sentido clásico»: A Theory of Justice (Cambridge, Mass., Harvard University Press, 1971), pág. 25 [trad. cast. de M. D. González Soler, Teoría de la Justicia (México/Madrid: F.C.E., 1979), pág. 43]. Ahora bien (y dando por buena la equiparación entre «teleológico» y «consecuencialista»), lo que hay que determinar es hasta qué punto el «sentido clásico» puede ser ensanchado de un modo que siga siendo todavía apreciablemente distinto del deontologismo. 
hasta haber analizado las estructuras consecuencialistas que prescinden de los dos componentes de la concepción utilitarista de lo bueno (es decir, no sólo del aditivismo, sino también de lo que Sen denomina «welfarism»): porque si las teorías que prescinden de esos dos elementos difieren aún en algún rasgo no trivial del deontologismo, por fuerza diferirán también las que prescinden sólo del segundo; y porque me interesan más aquéllas que éstas.

iv) $\mathrm{Al}$ abandonar los dos componentes que integran la concepción utilitarista de lo bueno quedan abiertas múltiples posibilidades. Puede pensarse, por ejemplo, en estructuras consecuencialistas que a la hora de determinar qué es lo que permite considerar «bueno»a un estado de cosas atribuyan relevancia no a un único factor -como la utilidad-, sino a varios (i.e., que hagan suya una concepción de lo bueno pluralista, y no monista); y que, sobre la base de esa pluralidad, consideren que el estado de cosas mejor es aquel en el que todos esos factores -o alguno de ellos, al que se atribuye prioridad lexicográfica- estén distribuidos de cierta manera, no aquel en el que su adición arroje un agregado total más alto (sea cual sea su distribución).

Incluso dejando al margen la sustitución del aditivismo por un criterio distributivo, una teoría consecuencialista que recurra a más de un principio para la identificación de los estados de cosas buenos adquiere un nivel de complejidad considerablemente mayor que el del utilitarismo: corre, de entrada, el riesgo de generar preferencias cíclicas $^{18}$; y ha de presuponer además que

${ }^{18}$ Tendríamos una preferencia cíclica siempre que el resultado de evaluar estados de cosas conforme a una cierta concepción de lo bueno ofreciera un resultado de este tipo; el estado de cosas $a$ es preferible al $b$, el $b$ al $c$ y el $c$ al $a$. Es lo que sucede, p. ej., con el caso del «liberal paretiano» (i.e., quien determina la bondad de los estados de cosas manejando dos principios: el principio débil de Pareto y un principio liberal según el cual la ordenación de preferencias de un individuo resulta decisiva en ciertos ámbitos protegidos frente a la interferencia de terceros) expuesto originariamente por A. K. Sen -en Collective Choice and Social Welfare (San Francisco, Holden-Day, 1970), cap. 6 [trad. cast. de F. Elías Castillo, Elección colectiva y bienestar social (Madrid, Alianza, 1976)]- y que ha generado ya un aluvión de comentarios, críticas y presuntas soluciones.

En realidad este tipo de problemas pueden surgir cuando alguno de los principios en juego (sea cual sea su contenido) produzca sólo ordenaciones parciales, es decir, cuando no sirva para jerarquizar por orden de preferibilidad cualquier par de estados de cosas pensable, sino sólo ciertos pares. Mackie ha demostrado concluyentemente que se pueden generar preferencias cíclicas siempre que se combinen dos principios lógicamente independientes $\mathrm{y}, a$ ) uno de ellos produzca sólo una ordenación parcial y se le atribuya prioridad lexicográfica 
los diferentes parámetros que definan a un estado de cosas como bueno son conmensurables, lo que para algunos representa un requisito imposible de satisfacer ${ }^{19}$. Pero ninguna de esas dificultades me parece insuperable. $\mathrm{Y}$ si se acepta que efectivamente no tienen por qué serlo, queda abierta la posibilidad de articular teorías consecuencialistas con concepciones pluralistas de lo bueno de muy diversos tipos (y en cualquier caso profundamente distintas de la del utilitarismo).

Pensemos, por ejemplo, en una teoría moral consecuencialista que en primer lugar considere valiosos aquellos estados de cosas en los que se dé una determinada distribución de la autonomía, entendida como asignación a cada individuo de ciertas capacidades o situaciones que le permiten un control efectivo sobre aspectos esenciales de su vida (entre las que se cuentan tanto la disponibilidad de ciertos recursos básicos que llenan de contenido su abstracta posibilidad de articular y materializar planes de vida, como el aseguramiento de un ámbito de acción libre de interferencia en el que pueda desarrollarse la opción elegida). En una estructura de este tipo la autonomía (o para ser más exactos, una determinada distribución de la misma, como por ejemplo aquella en la que sea mayor la del individuo peor situado) forma parte de una concepción de lo bueno relativa a estados de cosas. Y puede formar parte de ella como elemento prioritario pero no exclusivo: es decir, puede combinarse -aunque atribuyéndole prioridad lexicográfica sobre él- con otro principio que discrimine entre estados de cosas mejores y peores (por ejemplo, con uno que considere tanto más valioso un estado de cosas cuanto mayor sea el nivel de satisfacción de preferencias

sobre el otro; o b) al menos uno de ellos produzca sólo una ordenación parcial y no se atribuya prioridad lexicográfica a ninguno de los dos; cfr. John L. Mackie, «The Combination of Partially-Ordered Preferences» [1980], publicado póstumamente en J. L. Mackie, Persons and Values, Selected Papers, vol. II (Oxford, Clarendon Press, 1985), págs. 249-253.

${ }^{19}$ Para una crítica del consecuencialismo basada en la idea de la inconmensurabilidad, vid. p. ej., John Finnis, Natural Law and Natural Rights (Oxford, Clarendon Press, 1980), págs. 113-115; Id. Fundamentals of Ethics, cit. [vid., supra, nota 4], págs. 86-93; J. Finnis, J. M. Boyle y G. Grisez, Nuclear Deterrence, Morality and Realism (Oxford, Clarendon Press, 1987), pág. 252. El análisis más matizado que conozco de la idea de inconmensurabilidad es el de James Griffin, Well-Being, cit. [vid. supra nota 15], cap. V. Sobre la posibilidad de dilemas morales como producto de la inconmensurabilidad de ciertos valores, vid. la recopilación de Christopher W. Gowans (ed.), Moral Dilemmas (Nueva York/Oxford, Oxford University Press, 1987), que a mi juicio contiene los textos fundamentales sobre esta cuestión. 
individuales que se da en él). Porque, en efecto, no es preciso considerar que la bondad de un estado de cosas se agota en el dato de que en él la autonomía esté repartida apropiadamente: al decir que la autonomía es el elemento prioritario para apreciar la bondad de los estados de cosas y que consiste en la capacidad de elegir y desarrollar planes de vida (compatible con una capacidad igual de los demás), no está dicho que todos los planes de vida elegidos y desarrollados en esas condiciones y compatibles con el mantenimiento de las mismas sean igualmente valiosos. Lo que se dice es que según la concepción de lo bueno de la que hablamos el mantenimiento de la capacidad de elegir y de un ámbito de acción no interferido para desarrollar la opción elegida es más valioso que el contenido de la elección, no necesariamente que resulte indiferente elegir una cosa u otra. En términos muy gruesos: que aunque el máximo valor radicaría para esa concepción compleja de lo bueno en elegir autónomamente el plan de vida que ella misma defina (con arreglo a un principio complementario del de autonomía) como el mejor, por debajo de ese ideal se atribuye mayor valor a las condiciones de posibilidad de la elección autónoma de planes de vida, aunque los que se elijan resulten ser subóptimos, que a la adopción no autónoma del plan de vida óptimo (y nótese que la libre elección del plan de vida óptimo, siendo máximamente valiosa, en modo alguno puede ser obligatoria: si se postulara una «obligación de elegir libremente» el mejor plan de vida estaríamos en presencia de un auténtico monstruo lógico, ya que la idea de «estar obligado a elegir X libremente» es contradictoria).

Lo que tenemos entonces es una concepción pluralista, y no monista, de lo que hace bueno a un estado de cosas: en primer lugar, que se dé en él una determinada distribución de la autonomía; y cubierta esa exigencia -y sólo entonces-, que queden satisfechas el mayor número posible de preferencias individuales. Como trataré de mostrar en el próximo apartado, esa articulación pluralista -y con prioridad lexicográfica de uno de sus elementos sobre el otro- de la concepción de los estados de cosas buenos tiene una importancia capital a la hora de determinar la acción correcta dentro de una estructura consecuencialista, ya que permite entender en qué sentido lo correcto puede ser definido dentro de ella sin arbitrariedad como una función no estrictamente maximizadora de lo bueno. Si ello es así, una estructura de este tipo estará en las mejores condiciones para dar cuenta satisfactoriamente de la relación entre lo debido y lo supererogatorio, un punto en el que han tropezado tanto el consecuencialismo de tipo utilitarista (que al considerar exigible cualquier 
acto capaz de afectar positivamente al estado del mundo no deja espacio alguno para la categoría de los actos supererogatorios) como muchos críticos del consecuencialismo (que al alegar que todo individuo debe ser dispensado de la obligación de producir el máximo bien, ya que una responsabilidad tan desmesurada minaría su integridad en la medida en que le impediría asignar una atención preferente a sus propios proyectos, compromisos y lazos personales, encuentra la dificultad contraria de fundamentar y poner un límite a esa dispensa, si no se quiere que lo supererogatorio se extienda tanto que el espacio de los deberes positivos generales quede reducido a la insignificancia).

Una estructura de este tipo permite además una representación del papel que juegan los derechos en el marco de una teoría moral que me parece especialmente sugestiva. Estoy pensando en una concepción como la presentada por Scanlon y $\operatorname{Sen}^{20}$, que nos proponen que entendamos los derechos como metas u objetivos [«goals»]. En ella los derechos se conciben primariamente como capacidades o situaciones de los individuos cuyo aseguramiento para cada uno se considera valioso, de manera que su presencia o ausencia en un estado de cosas determina la mayor o menor bondad del mismo (con prioridad lexicográfica sobre otros posibles factores determinantes también de dicha bondad); y una vez incorporados los derechos a la valoración de los estados de cosas, la selección de la acción correcta toma en cuenta su eficacia causal para producir o mantener esos estados valiosos. Frente a un punto de vista deontológico clásico, que considera los derechos como límites o constricciones referidos directamente a las acciones, y no como elementos incorporados a la valoración de estados de cosas, un «sistema de derechos como objetivos» puede ofrecer ventajas importantes (que aquí no cabe sino mencionar brevemente): al identificar las acciones debidas a través de una evaluación consecuencialista, integrando satisfacciones y violaciones de los derechos en la valoración de estados de cosas, permite tomar en cuenta las interdependencias multilaterales

${ }^{20}$ Cfr. T. M. Scanlon, «Rights, Goals and Fairness», cit., y A. K. Sen, «Rights and Agency», cit. [vid. supra, nota 7]. Me atrevería a sugerir que F. Laporta no se mueve muy lejos de esta línea cuando caracteriza los derechos como «"bienes” relevantes, es decir, situaciones o estados de cosas a los que el sistema confiere una cierta importancia, un cierto valor...», de manera que el valor atribuido a esas situaciones o estados de cosas proporciona una justificación para articular normativamente su protección a través de técnicas diversas; vid. Francisco J. Laporta, «Sobre el concepto de derechos humanos», en Doxa, 4 (1987), 23-46, pág. 30. 
de las acciones (es decir, los casos en los que el único medio de satisfacer un derecho es la violación de otro, quizás incluso de menor importancia) y hace posible un tratamiento más adecuado de los «conflictos entre derechos»; y permite entender en qué sentido los derechos no son meramente el correlato de deberes infranqueables que pesan sobre los demás, definidos a priori de modo legalista a través de fórmulas rígidas, sino el fundamento de muy diversas técnicas normativas de protección (imposición de deberes, concesión de poderes o inmunidades, etc.), cuya entrada en juego y contenido específico dependerá además de lo que en cada caso exijan -y permitan- las circunstancias para el aseguramiento de aquellos objetivos.

v) Habría que preguntarse si una estructura consecuencialista como la que se acaba de describir difiere o no en realidad de una moral deontológica. Formalmente la diferencia es muy fácil de establecer. Una moral deontológica atribuye valor (o desvalor) intrínseco a las acciones: no tiene por qué contar con un criterio de ordenación de estados de cosas por su mayor o menor bondad (o incluso puede considerar que una idea semejante carece de sentido), y en cualquier caso el valor de las acciones no se deriva del de aquello que resulta de ellas ${ }^{21}$. Lo relevante para el deontologismo son las acciones en su dimensión de actividad (praxis), no en su dimensión de producción de algo (poiesis). Pero lo que interesa saber es si en este caso la diferencia es sólo verbal o aparente: porque podría suceder que a través de sucesivos cambios y acoplamientos hubiésemos llegado a una suerte de deontologismo encubierto, al abandono real del espacio consecuencialista.

Aunque al tratar de marcar los límites de ese espacio podemos embarcarnos en una mera disputa terminológica, me parece posible afirmar que hay al menos un punto en el que esta forma compleja de consecuencialismo difiere aún de lo que suele considerarse típico del deontologismo. Si la satisfacción o violación de los derechos se incorpora a la evaluación de los estados de

${ }^{21}$ Cfr., p. ej., Philippa Foot, «Utilitarianism and the Virtues», en Mind, 94 (1985), 196-209 [ahora en Scheffler, Consequentialism and its Critics, cit. -supra, nota 2-, págs. 224-260, por donde se cita; esp. págs. 227 y sigs.]. Alfonso Ruiz Miguel expresa la idea con claridad: «[...] las éticas de tipo deontológico ponen el acento en el valor o falta de valor de las acciones en sí mismas consideradas, con especial referencia a las intenciones, disposiciones de carácter de las que el agente pueda ser responsable o rasgos de la personalidad que determinadas acciones denotan [...]»; vid. A. Ruiz Miguel, La justicia de la guerra y de la paz (Madrid, Centro de Estudios Constitucionales, 1988), págs. 145-146. 
cosas, parece difícilmente discutible que un estado de cosas será tanto más valioso -caeteris paribus- cuanto menor sea el número de violaciones del mismo tipo que se dé en él ${ }^{22}$. $\mathrm{O}$ dicho con otras palabras: que si la violación del derecho $\mathrm{D}$ de un individuo es el único modo de evitar la violación del mismo derecho de un número mayor de individuos, una estructura consecuencialista como la que se ha presentado considerará que, como mínimo, dicha violación está moralmente permitida. Podría pensarse que más bien habría de calificarla por necesidad como obligatoria: pero si la autonomía de los individuos se ha integrado con prioridad lexicográfica en la valoración de los estados de cosas, quizás un agente podría invocarla para eximirse de realizar aquello que produciría el mayor bien en las circunstancias del caso (i.e., el menor número de violaciones del mismo tipo). En una genuina teoría moral deontológica, por el contrario, la violación de un derecho, aun en esas circunstancias, no podría calificarse ni tan siquiera como permitida: es decir, no se trata meramente de que las morales deontológicas no consideren obligatorio producir el mayor bien en circunstancias semejantes, es que consideran obligatorio no producirlo (seguramente porque desde su propia óptica no tendría sentido hablar en ese caso de «un mayor bien»). Ese rasgo de las morales deontológicas puede valorarse como un mérito (en la medida en que probablemente coincide con puntos de vista presentes en nuestra «moral de sentido común» a los que no parece fácil renunciar), o un demérito (por cuanto podría ser difícilmente compatible con una idea ampliamente aceptada de racionalidad, tal y como extensa y detalladamente ha sostenido Scheffler) ${ }^{23}$ : pero sea como fuere

${ }^{22}$ Lo discute John M. Taurek, «Should the Numbers Count?», en Philosophy and Public Affairs, 6 (1977), 293-316. Pero aunque una violación no sea menos mala que varias, será al menos igualmente mala; y entonces podría sostenerse, como mínimo, que estará permitido ejecutar aquélla para evitar éstas, lo que, como se verá, es todo cuanto se precisa para marcar la diferencia con el deontologismo.

${ }^{23}$ Vid. S. Scheffler, The Rejection of Consequentialism, cit. -supra, nota 7-, en especial cap. 4; Id., «Agent-Centred Restrictions, Rationality and the Virtues», en Mind, 94 (1985), 409-419 [ahora en Scheffler (ed.), Consequentialism and its Critics, cit. -supra, nota 2-, págs. 243-260]. 
-y no pretendo ahora entrar en ello-, sirve como piedra de toque para demostrar que el tipo de estructura consecuencialista que se ha examinado en último lugar es todavía diferenciable de lo que suele entenderse como deontologismo (aunque seguramente se encuentre más cerca de él en sus contenidos que otras formas de consecuencialismo como las utilitaristas).

vi) La divisoria entre consecuencialismo y deontologismo comienza ya a difuminarse si se da un paso más y se considera a la acción productora como parte del estado de cosas producido. Aunque algunos rechazan de plano esa posibilidad ${ }^{24}$, alegando que su admisión convertiría al consecuencialismo en una etiqueta vacía, no falta quien, como Sen, sostenga que ese rechazo carece de fundamento y no es en el fondo sino un residuo de la estrecha asociación histórica (hasta llegar inconscientemente casi a su equiparación) entre consecuencialismo y utilitarismo ${ }^{25}$. En realidad este paso no representa apenas nada si las acciones se contemplan desde fuera, como puros eventos, de manera que la evaluación de los estados de cosas (incluso incorporándoles las acciones productoras) siga efectuándose desde un punto de vista impersonal ${ }^{26}$. Si en vez de decir que en $p$ muere una persona y en $q$ mueren diez, se dice que en $p$ se mata a una persona y en $q$ se mata a diez -incorporando la acción productora al estado de cosas producido-, no deja de ser cierto que si producir $p$ es la única forma de evitar $q$ lo habrá igualmente en las acciones del mismo tipo que se evitan al realizarla; $y$, por consiguiente, la incorporación de las acciones productoras a los estados de cosas no ha alterado la valoración relativa de éstos. Lo que sí representa una transformación de envergadura es la contemplación de las acciones en primera persona desde el punto de vista del agente: no como un rasgo impersonal de uno entre varios mundos posibles, sino como algo que hago precisamente yo. Y si ello es así la evaluación de los estados de cosas deja de ser «neutral respecto al agente» y se convierte en «relativa al agente», por cuanto habrá de reflejar la circunstancia de que éste está implicado en cada uno de esos estados de cosas de distintos modos (en unos precisamente como agente y en otros como espectador). Lo que eso implica es que el valor del estado de cosas $p$, pongamos

${ }^{24}$ Por ejemplo, Charles Taylor, «The Diversity of Goods», en A. K. Sen y B. Williams (eds.), Utilitarianism and Beyond (Cambridge, Cambridge University Press, 1982), págs. 129-144, pág. 144. No la excluye radicalmente Raz, si bien la califica como una «ficción» que puede provocar innecesarios desacuerdos verbales; cfr. Joseph Raz, The Morality of Freedom (Oxford, Clarendon Press, 1986), pág. 270.

${ }^{25}$ Cfr. A. K. Sen «Rights and Agency», cit. -supra, nota 7-, pág. 212; Id. «Evaluator Relativity and Consequential Evaluation», en Philosophy and Public Affairs, 12 (1983), 113-132, pág. 118.

${ }^{26}$ Cfr. Anselm W. Müller, «Radical Subjectivity: Morality versus Utilitarianism», en Ratio, 19 (1977), 115-132 (citado por J. Finnis, Fundamentals of Ethics, cit. -supra, nota 4-, pág. 114). 
por caso, ya no es el mismo para aquel que mata y para cualquier otro: para el primero resulta especialmente disvalioso -ya que es $s u$ acción la que queda incorporada al estado de cosas $p$-, de manera que al avaluar $p$ y $q$ una misma moral consecuencialista podría dar como resultado que él no debe realizar $p$ ni tan siquiera para evitar $q$ y que sin embargo cualquier otro no tenga que (o incluso no deba) abstenerse de impedir $q$ para impedirle a él que produzca $p$ (en uno y otro caso sin violar derechos) cuando sólo le sea posible impedir una de las dos cosas.

Que el consecuencialismo pueda adaptarse de manera que genere razones relativas al agente es algo que las más de las veces no se acepta ${ }^{27}$. No sólo se suele dar por descontado que es una moral neutral respecto al agente, sino que en ocasiones se ha visto en ello justamente su mayor virtud ${ }^{28}$. Sea como fuere, lo que habría que preguntarse, una vez más, es si el tipo de teoría moral resultante -una estructura consecuencialista en la que se tomaran en cuenta las acciones productoras de los estados de cosas de manera que su evaluación fuese relativa al agente diferiría aún de lo que suele considerarse como deontologismo. Y creo que sí lo haría: porque un consecuencialismo de este tipo, aun atribuyendo cierto valor o desvalor a la acción productora en sí misma, deriva su concepto de «acción correcta» de la evaluación de los estados de cosas en su conjunto, es decir, de la valoración de un todo del que la acción ejecutada es sólo una parte. Sólo llegaría a ser indistinguible del deontologismo si dentro de ese todo se atribuye a la acción productora un valor o desvalor de tal magnitud que por principio el resto de sus elementos -lo producidono pueda nunca desbancar esa valoración. Por supuesto la posibilidad de seguir considerando "consecuencialista» un cierto tipo de teoría moral depende también de la extensión que concedamos al concepto de «deontologismo»: si se acepta que puede seguir calificándose como deontológica una

${ }^{27}$ Cfr. T. Nagel, «The Limits of Objectivity», cit. -supra, nota 8-, pág. 119; Donald H. Regan, «Against Evaluator Relativity: A Response to Sen», en Philosophy and Public Affairs, 12 (1983), 93-112.

${ }^{28}$ Es el caso de Parfit, que sostuvo que las morales relativas al agente son «directa y colectivamente auto-refutatorias», un riesgo frente al que sería inmune el consecuencialismo precisamente por ser neutral respecto al agente: cfr. Parfit, Reasons and Persons, cit. -supra, nota 7-, cap. 4. El argumento de Parfit ha sido lúcidamente criticado por Arthur Kuflik, "A Defense of Common-Sense Morality», en Ethics, 96 (1986), 748-803; y Parfit ha aceptado en buena parte la objeción; vid. D. Parfit, «Comments», en Ethics, 96 (1986), 832-872, pág. 851. 
moral que no excluya de plano la relevancia de las consecuencias, siempre y cuando niegue que la acción correcta sea siempre la que produce el mejor estado de cosas (incluido en él la acción que lo produce) ${ }^{29}$, entonces los extremos se han aproximado hasta tocarse en un punto del que resulta difícil afirmar si más bien se encuentra aún en el campo consecuencialista o en el deontológico, o si debe por contra considerarse como una suerte de vía media entre ambos. Pero no sólo resulta difícil, sino además estéril: porque no creo que sirva a la clarificación de nuestras ideas el manejo de los conceptos como si fueran lechos de Procusto.

\section{Causalidad y consecuencialismo}

La idea de causalidad entra en escena al pasar de los juicios acerca de la bondad de los estados de cosas a los juicios relativos a la corrección de las acciones. Pero antes de examinar si trae consigo o no algún problema insalvable para cualquier clase de estructura consecuencialista, me parece oportuno adelantar algunas precisiones en torno al concepto de omisión (que servirán para ahorrarnos más tarde algunos equívocos sumamente enojosos).

i) Obsérvese que, en principio, la cuestión de determinar qué es una omisión no se confunde con la de establecer qué omisiones son obligatorias y cuáles están permitidas o prohibidas (que dependerá de lo que establezca el sistema normativo -del tipo que sea- que tomemos como referencia). En ese sentido cabría afirmar que en una ocasión «o» un agente omite todas las acciones que no ejecuta y que podría ejecutar en $o$, y ello en el doble sentido de que 1) genéricamente es capaz de realizar acciones de ese tipo y 2) la concreta ocasión $o$ ofrece una oportunidad de realizarlas. Sucede sin embargo, como es bien sabido, que para algunos una definición de este tipo sería excesivamente amplia. Entre los penalistas, por ejemplo, predomina -aunque desde luego no es unánime- la idea de que sólo cabe hablar de omisión si concurre además otra circunstancia: que la acción que no se ejecuta sea una acción debida. Desde ese punto de vista, en una ocasión o un agente sólo «omite» las acciones que no ejecuta y podía y debía ejecutar en $o$ (a tenor de lo establecido por algún sistema normativo que se toma como referencia) ${ }^{30}$.

Causalidad, consecuencialismo y deontologismo

${ }^{29}$ Vid. Sen, «Evaluator Relativity...», cit. -supra, nota 25-, págs. 130-132.

${ }^{30}$ Vid., por todos, el reciente artículo de Enrique Gimbernat, «Sobre los conceptos de omisión y comportamiento», en Anuario de Derecho Penal y 
Pero no creo que merezca la pena embarcarse en una disputa como ésa, a mi juicio meramente verbal. De hecho, quienes propugnan un concepto normativo de omisión acaban sintiendo la necesidad de contar con un tercer concepto, intermedio entre el puro no hacer y lo que para ellos constituye una genuina «omisión», que resulta equivalente a lo que llamaría «omisión» quien maneje esta noción en un sentido previo a cualquier clase de calificación deóntica $^{31}$. Y este último sentido me parece preferible simplemente porque no nos obliga a explicitar a cada paso las presuposiciones normativas que manejamos implícitamente cada vez que decimos que un sujeto «omite» algo.

Me parece, además, que la insatisfacción que produce a veces el concepto pre-normativo de omisión (y que explica seguramente por qué se llega a postular en su lugar un concepto normativo) admite una explicación sencilla que en modo alguno nos urge a su abandono. La clave reside, según creo, en que, como ha señalado Mackie ${ }^{32}$, decir que un agente "omite la acción p" es una de las descripciones posibles de un suceso que también podría ser descrito como «omite la acción $q$ (o $r$, o $s \ldots$, etc.)», o, alternativamente, bien como «ejecuta la acción $v$ (o $w$, o $x$..., etc.)» o como «no hace nada en absoluto». El conjunto de acciones -seguramente muy amplio- de las que se puede decir con sentido que el agente omite su realización en $o$ está limitado por su capacidad y por las oportunidades presentes en $o^{33}$. Pero, aun

Ciencias Penales, 40 (1987), 579-607, y la bibliografía allí citada. La tesis del carácter normativo del concepto de omisión, dominante entre los penalistas, ha sido criticada por Manuel Atienza, «Para una teoría general de la acción penal», en Anuario de Derecho Penal y Ciencias Penales, 40 (1987), 5-14, pág. 7, nota 6. Agradezco a Blanca Mendoza el haberme llamado la atención sobre ambos textos.

31 Es lo que le sucede a Gimbernat (op. cit.), que distingue el puro no hacer del «comportamiento pasivo», y éste a su vez de -lo que es para él- la genuina «omisión». Quien por el contrario maneje un concepto pre-normativo llamará «omisión» a lo que él denomina «comportamiento pasivo» $\mathrm{y}$ «omisión prohibida» a lo que denomina «omisión». No acabo de verle objeto al empeño que pone Gimbernat -que quizá no advierte que lo que anda en juego no son más que definiciones estipulativas- en demostrar que sólo el uso que él propugna es «correcto».

32 John L. Mackie, «The Grounds of Responsibility», en P. M. S. Hacker y J. Raz (eds.) Law, Morality and Society, Essays in honour of H. L. A. Hart (Oxford, Clarendon Press, 1977), págs. 175-188, págs. 176 y 179.

${ }^{33}$ Nótese que lo que el agente omite en una ocasión dada es la disyunción de las acciones posibles y no ejecutadas en dicha ocasión, no la conjunción de todas ellas; porque si bien el agente contaba con la capacidad y la oportunidad de realizar cada una de ellas (o ciertas combinaciones limitadas de ellas), no tenía ni la capacidad ni la oportunidad de realizarlas todas. 
con esa restricción, la gama de descripciones posibles de un suceso (empleando el término en un sentido ad hoc, que pretende englobar a la vez la ejecución de una acción positiva y la pura pasividad de un agente en una ocasión dada) sigue siendo considerablemente extensa. Y lo que sucede, simplemente, es que de todas las descripciones lógicamente posibles (positivas o negativas) sólo alguna o algunas resultan interesantes o incluso apropiadas desde el punto de vista pragmático: y cuáles lo sean, y cuáles no, depende obviamente de los propósitos implícitos en las situaciones de comunicación en que se selecciona y usa alguna de esas descripciones.

Una de las situaciones típicas en las que cierto comportamiento activo o la pura pasividad del agente admite ser descrito -sin extravagancia pragmática- como la omisión de alguna de las acciones posibles (y no realizadas) en esa ocasión, es aquella en que la acción cuya omisión se destaca era una acción debida o esperada (según algún sistema normativo -o según expectativas basadas en regularidades de conducta que no obedezcan al seguimiento de normas- que toma como referencia quien habla). De ahí a sostener que el agente sólo «omite» lo que tenía el deber de hacer puede no haber más que un paso. Pero un paso que no creo que tenga que ser dado: porque las expectativas -deónticas o de otro tipo- que determinan qué descripciones en términos de omisión no son pragmáticamente extravagantes pueden ser sumamente cambiantes (dependiendo de los puntos de referencia de quien describe); pero las circunstancias de capacidad y oportunidad, que circunscriben el repertorio de descripciones posibles en términos de omisión entre el que habrá que seleccionar las que sean en cada caso pragmáticamente apropiadas, no vienen definidas por presuposiciones normativas de ninguna clase.

ii) Tras estas precisiones, creo que podemos pasar ya a analizar de qué modo entra en juego la idea de causalidad en el marco de una teoría moral con estructura consecuencialista. Adelantaré en primer lugar una explicación global y sólo después pasaré a considerar hasta qué punto dicha explicación resultaría minada por el argumento de Nino.

Utilizaré como apoyo para presentar mi punto de vista algunos elementos tomados -con cierta libertad- de la teoría de la acción de Von Wright ${ }^{34}$. Supongamos que sólo hay tres estados

${ }^{34}$ De la que por supuesto el autor finés ha ido produciendo distintas versiones a lo largo del tiempo. La que tomo como referencia es la contenida en G. H. von Wright, «Norms, Truth and Logic», en Von Wright, Practical Reason, 
de cosas posibles, $p, q$ y $s$. El estado de cosas existente (p. ej., $p$ ) puede tender a la estabilidad o al cambio: que el estado de $\operatorname{cosas} p$ tiende a la estabilidad (simbólicamente, $p T p$ ) quiere decir que no se transformará en otro a menos que alguien produzca la transformación; que tiende al cambio (por ejemplo, hacia $q: p T q$ ), que existen cursos causales en marcha que harán que se transforme en $q$ a menos que alguien impida la transformación.

Cuando el estado de cosas existente tiende a la estabilidad ello ofrece una ocasión para acciones productoras (de estados de cosas diferentes: p. ej., a partir de $p T p$, para Prq o para Prs). Qué acciones productoras sean posibles en cada situación es algo que depende de qué estados de cosas sean «causalmente accesibles mediante la acción humana»a partir del existente, lo que obviamente está condicionado no sólo por las leyes de la naturaleza, sino también por la posesión de ciertos conocimientos y el perfeccionamiento de ciertas técnicas. Entre dos estados de cosas, por otra parte, la relación «causalmente accesible mediante la acción humana» no tiene por qué ser simétrica (si en $p$ yo estoy vivo y en $q$ muerto -y en todo lo demás ambos estados de cosas son idénticos-, $q$ es causalmente accesible para la acción humana desde $p$, pero no a la inversa). Por último, cuando existe una ocasión para cierta clase de acción productora (para Prq, por ejemplo) existe al mismo tiempo una ocasión para la omisión de dicha acción (i.e., para ]Prq).

Cuando el estado de cosas existente tiende al cambio, ello ofrece una ocasión para acciones mantenedoras (p. ej., para $M p$ a partir de $p T q$ o de $p T s$ ). Del mismo modo que no todas las transformaciones pueden ser producidas mediante acciones humanas, tampoco todas las que ya están en marcha pueden ser impedidas: no todas las transformaciones en curso constituyen una ocasión para una acción mantenedora. Puede ocurrir, por otra parte, que un estado de cosas que tiende al cambio suponga una ocasión para acciones productoras de otros estados de cosas distintos de aquel en el que se está transformando el existente

Philosophical Papers, vol. I (Londres, Basil Blackwell, 1983), págs. 130-209; vid. especialmente págs. 173-175. Con respecto a la notación original, he reemplazado el operador «B» («bringing about») por «Pr» («producir»); y el operador «S» («sustaining»), por «M» («mantener»). El símbolo «7》, antepuesto a los operadores Pr o M, indica que se omite la acción productora o mantenedora correspondiente (pero no debe ser considerado como una conectiva: vid. ibid, págs. 193-195). La idea de que pTp o pTq representen tendencias del mundo entraña una modificación -en la que sigo a M. Atienza, «Para una teoría general de la acción penal», cit., pág. 10, nota 8- con respecto a la presentación de Von Wright (en la que pTp, pT-p, etc, describen sucesos). 
(i.e., cabe que $p T q$ ofrezca una ocasión para $P r s$ ). En cualquier caso, cuando existe una ocasión para cierta clase de acción mantenedora (para $M p$ ) o de acción productora de un estado de cosas diferente de aquel hacia el que tiende el actual (Prs a partir de p Tq), existe al mismo tiempo una ocasión para las omisiones correspondientes ( $\mathrm{Mp}$, $7 \mathrm{Prs}$ ).

Podemos preguntarnos ahora cuáles de esas acciones u omisiones serían consideradas en cada caso obligatorias o prohibidas por parte de diferentes tipos de teorías morales con estructura consecuencialista. Ello dependerá en primer lugar de cuál sea el estado de cosas actual y cuáles las tendencias del mundo (a la estabilidad o al cambio), de qué estados de cosas sean causalmente accesibles mediante la acción humana a partir del existente y qué transformaciones en curso puedan ser impedidas. A partir de ahí, cada estructura consecuencialista nos llevará por un rumbo distinto según la forma en que ordene por su valor los estados de cosas en juego y según el modo en que articule el paso de los juicios acerca de la bondad de los estados de cosas a los juicios acerca de la corrección de las acciones.

Tomemos, por ejemplo, el utilitarismo de actos. Supongamos que la suma de las utilidades individuales en $s$ es mayor que en $q$, y en $q$ mayor que en $p(s>q>p)$. Sin necesidad de examinar una por una todas las situaciones posibles para determinar cuál sería en cada caso la acción moralmente obligatoria -labor que resultaría demasiado tediosa y que dejo para el improbable y sufrido lector de estas líneas-, es fácil ver cómo se destacan rápidamente algunos rasgos significativos: en general, será obligatorio actuar o abstenerse de actuar de manera que el estado de cosas resultante (producido o mantenido) sea, en términos utilitaristas, el mejor de los posibles. Esa es, sin duda, al margen de otros muchos defectos del utilitarismo que podrían traerse a colación, una exigencia muy fuerte. Apenas habría acciones moralmente indiferentes; y ninguna sería supererogatoria, recayendo sobre las espaldas de cada uno de nosotros la inmensa carga de no dejar de producir ningún cambio posible hacia un estado de cosas mejor.

Es cierto que ese peso ingente podría quedar mitigado si, manteniendo intactos la concepción de lo bueno y el criterio directo de determinación de la acción correcta que son propios del utilitarismo de actos, se modulan adecuadamente los criterios de adscripción de responsabilidad. Y más aún si conservando la concepción utilitarista de lo bueno se opta en cambio por un criterio indirecto de identificación de las acciones correctas. Pero lo que más me interesa destacar es la transformación, comparativamente 
mucho más profunda, que resultaría de articular una estructura consecuencialista con una concepción de lo bueno completamente distinta.

Pensemos en una estructura como la descrita en el apartado anterior, que considera tanto más valioso un estado de cosas cuanto más cercano se halle de un cierto esquema de distribución de la autonomía; y, alcanzada esa distribución idónea -a la que se atribuye prioridad lexicográfica-, cuanto mayor sea el nivel de satisfacción de preferencias individuales que se da en él. Una teoría moral estructurada de este modo no convierte en obligatorias todas las acciones u omisiones productoras o mantenedoras del mejor estado de cosas posible: pero la razón de que no lo haga radica en la forma en que está articulada su concepción de lo bueno, no en que con ella hayamos salido fuera del marco consecuencialista. Esta idea merece ser desarrollada con cierto detenimiento.

Llamemos «punto DOA» a aquel que representa la distribución óptima de la autonomía. Si dos estados de cosas $-p$ y $q$ - han alcanzado ese punto o se encuentran a igual distancia de él, de ellos dos es más valioso aquel (p. ej., $p$ ) en que se dé un mayor nivel de satisfacción de preferencias individuales $(p>q)^{35}$. Pero lo que eso quiere decir es que las acciones $\mathrm{u}$ omisiones productoras o mantenedoras de $p$ son mejores que las acciones $\mathrm{u}$ omisiones productoras o mantenedoras de $q$, no que son obligatorias. Serán obligatorias las acciones $\mathrm{u}$ omisiones estrictamente necesarias para alcanzar o no abandonar el punto DOA, o para aproximarnos a él tanto como sea posible: pero optar entre todas ellas precisamente por las que aseguran además un nivel más alto de satisfacción de preferencias individuales no es obligatorio, sino supererogatorio. Sostener lo contrario -como traté de explicar anteriormente- equivaldría a vaciar de contenido el valor de la autonomía, que se realiza cuando el sujeto está en condiciones de elegir y elige libremente (de un modo compatible con una igual capacidad de elección libre de los demás), no cuando elige algo determinado. De este modo, y en comparación con el utilitarismo de actos, se reduce drásticamente el número de acciones positivas obligatorias (o, lo que es lo mismo, de omisiones prohibidas). Y la moral resultante no

${ }^{35}$ Si uno de los dos está más cercano al punto DOA que el otro entonces es necesariamente mejor que él -aunque en este último sea más alto el nivel de satisfacción global de preferencias individuales-, en virtud de la prioridad lexicográfica que dentro de esta concepción pluralista de lo bueno se atribuye a un determinado esquema de distribución de la autonomía. 
sólo se desprende de exigencias desmedidas y sofocantes, sino que además da cabida a la idea de comportamientos valiosos pero situados más allá de lo exigible. Tendremos, en definitiva, una estructura consecuencialista en la que lo correcto no se define automáticamente como la maximización de lo bueno: pero es la articulación interna de su concepción de lo bueno, y no un deslizamiento subrepticio hacia el deontologismo, lo que le permite caracterizar lo correcto como una función no maximizadora de lo bueno.

iii) Creo que ya estamos en condiciones de apreciar de qué modo maneja el consecualismo la idea de causa y de entender por qué no se ve envuelto en el cuatrilema en el que a juicio de Nino quedaría aprisionado. Cuando una teoría moral consecuencialista -de cualquier tipo- califica deónticamente una acción, lo hace a la vista de su eficacia causal para producir o mantener determinados estados de cosas. Pero el juicio según el cual ciertas acciones son causalmente eficaces para la producción o el mantenimiento de ciertos estados de cosas tiene una naturaleza completamente distinta de la del juicio (de imputación) que individualiza una determinada acción u omisión como la causa de un cierto resultado: porque el primero, a diferencia del segundo, no encierra presuposiciones normativas de ninguna clase.

El primer tipo de juicios -sobre la eficacia causal de las acciones- descansa tan sólo en nuestro conocimiento parcial de las regularidades causales que se dan en el mundo. Sobre la base de ese conocimiento incompleto, acumulado a través de un proceso inductivo vastísimo y sumamente complejo ${ }^{36}$, estamos en condiciones de determinar de qué modos sería posible intervenir en el curso de los acontecimientos, manipulándolo de manera que tome una dirección nueva o recupere la que está abandonando. Decir que a partir de $p T p$ hacer $\phi$ sería una manera de producir el estado de $\operatorname{cosas} q$ (o, a partir de $p T q$, que $\phi$ sería una manera de mantener $p$ ) es adelantar un condicional contrafáctico que, de ser verdadero, deriva su verdad de las regularidades causales del mundo que conocemos de manera incompleta. Y de nada más: que una acción sea causalmente eficaz en unas circunstancias dadas para producir o mantener cierto estado de cosas no depende de que esas circunstancias se correspondan o no

${ }^{36}$ Cfr. John L. Mackie, The Cement of the Universe. A Study of Causation (Oxford, Oxford University Press, 1974; reimp. con un nuevo Prefacio, 1980), cap. 3. 
con el curso usual de los acontecimientos, ni de expectativas deónticas de ninguna clase. Y tampoco depende, aunque a primera vista pudiera parecer lo contrario, de que efectivamente se produzca o mantenga el estado de cosas en cuestión. El juicio sobre la eficacia causal de las acciones es un juicio ex ante, en el que se afirma que si en las circunstancias presentes se ejecuta cierta acción resultará tal o cual estado de cosas a menos que ello se evite mediante una nueva acción (a su vez causalmente eficaz en las nuevas circunstancias creadas por la acción anterior).

Quizá pueda pensarse que toda esta explicación no puede extenderse a las omisiones. Pero la calificación deóntica que da el consecuencialismo a las omisiones deriva simplemente de la consideración de la eficacia causal de las acciones omitidas: si ciertas acciones productas o mantenedoras se califican -a la vista de los estados de cosas que son capaces de producir o mantener- como obligatorias, su omisión estará prohibida (y si se califican como prohibidas, su omisión será obligatoria). Como traté de explicar anteriormente, decir que lo que el agente ha hecho ha sido, por ejemplo, 7 Prp, no es más que una manera de describir su absoluta pasividad o su realización de una acción positiva distinta de Prp -en una ocasión en que disponía de la oportunidad de Prp- que resulta especialmente apropiada desde el punto de vista pragmático cuando se considera que Prp era en esa situación una acción obligatoria o prohibida (con lo que su omisión se destaca a modo de reproche o alabanza).

A diferencia de los juicios sobre la eficacia causal de las acciones, los juicios de imputación -aquellos que en contextos atributivos seleccionan ex post cierta acción $\mathrm{u}$ omisión como la causa de un estado de cosas, que se presenta entonces como su resultadosí encierran presuposiciones normativas. Porque los juicios de imputación aíslan, entre todas las condiciones necesarias y conjuntamente suficientes para la producción del resultado, aquella -positiva o negativa- que «marca la diferencia» respecto a las «condiciones normales del contexto» (lo que Mackie denomina «campo causal» ${ }^{37}$ ); y la identificación de esas «condiciones normales» que operan como trasfondo de los juicios de imputación (es decir, del «campo causal» que ha de tomarse como referencia) incluye entre otras cosas expectativas deónticas, de manera que la selección de la causa siempre es

${ }^{37}$ Cfr. Mackie, The Cement of the Universe, cit., [reimp. 1980], págs. 34-35 y 120. 
relativa en parte a un sistema normativo dado. Y no sólo cuando se identifica como la causa una omisión, sino también cuando se individualiza como tal una acción: porque en este caso se está presuponiendo que las «circunstancias normales del contexto» no incluyen la ejecución de otra acción causalmente eficaz para cortar o desviar el curso causal en marcha tras la realización de la primera (ya que en caso contrario no se seleccionaría como la causa la primera acción, sino la omisión de la segunda). Nótese que al afirmar que cierta acción es en determinadas circunstancias causalmente eficaz para la producción o mantenimiento de un cierto estado de cosas no se está diciendo que, si finalmente ese resultado se produce o mantiene, aquella acción deba ser identificada automáticamente como su causa: eso dependerá del sistema normativo que se tome como referencia para la determinación del «campo causal», que puede llevar a identificar como la causa una omisión posterior o incluso otra acción u omisión previa.

Si para calificar deónticamente las acciones u omisiones una teoría moral consecuencialista necesitara saber previamente si son o no la causa de determinados estados de cosas, ciertamente quedaría aprisionada en el cuatrilema expuesto por Nino (porque en ese caso los juicios de imputación serían un prius respecto a la calificación deóntica de las acciones). Pero, por fortuna para el consecuencialismo -en cualquiera de sus formas-, no es ése su modus operandi: una vez establecido el valor relativo de los diferentes estados de cosas (que cada teoría consecuencialista fijará de modo diferente según la naturaleza de su concepción de lo bueno), la calificación deóntica de las acciones depende tan sólo de juicios acerca de su eficacia causal; y a la vista de esas calificaciones deónticas -tomadas como base para la definición del «campo causal» correspondiente- podrá realizar juicios de imputación (de manera que éstos dependerán conceptualmente de aquéllas, y no a la inversa). Esos juicios de imputación serán distintos de los que resultarían de seguir el criterio del «sentido común» (o, como dice Nino, el «concepto ordinario de causa»), ya que la definición de las circunstancias normales del contexto o campo causal relevante dependerían en el primer caso de las calificaciones deónticas generadas por la teoría consecuencialista y en el segundo de normas provenientes en parte de la moral positiva. Y por eso toda teoría consecuencialista estaría en condiciones de hacer cualquiera de estas dos cosas: o bien seguir llamando «la causa» de un determinado resultado a lo que el sentido común identifica como tal, pero advirtiendo a continuación que usa un criterio de responsabilidad 
que no depende en absoluto de esa identificación; o bien realizar los juicios de imputación sobre la base de sus propias calificaciones deónticas, seleccionando entonces como «la causa» de un determinado resultado acciones u omisiones que el sentido común no identificaría necesariamente como tales (dependiendo el mayor o menor alejamiento entre ese concepto renovado de causa y el correspondiente al sentido común del tipo de teoría consecuencialista de que se trate).

iv) Ciertamente, algunas propuestas conocidas de ética normativa han quedado atrapadas en algo parecido (pero según trataré de demostrar, no idéntico) a la cuarta y a la tercera de las cuatro posibilidades igualmente insatisfactorias entre las cuales, a juicio de Nino, ha de optar el consecuencialismo: pero no creo que ello se deba a su estructura consecuencialista, sino a razones de otro tipo.

El utilitarismo de actos, por ejemplo, extiende nuestra responsabilidad negativa de tal modo que acaba resultando altamente contraintuitivo. Pero ese ensanchamiento desmesurado de los deberes positivos que pesarían sobre nosotros (es decir, del número de omisiones prohibidas) no deriva del empleo de un concepto de causa no restringido por la cláusula «en las condiciones normales del contexto» (en la línea de la cuarta de las posibilidades que compondrían el cuatrilema), sino de su concepción de lo bueno, de la forma específica en que valora la bondad de los estados de cosas, que es la que determina -en conjunción con juicios, no de imputación, sino relativos a la eficacia causal de las acciones- que el número de acciones obligatorias sea más o menos amplio. Con otras palabras: no es que por emplear un concepto de causa impropio o desnaturalizado (en comparación con el que se usa en los juicios de imputación del «sentido común») se obtenga una moral inaceptable por desmesurada, sino más bien al revés, que por postular unos deberes desmesurados se identifica ahora como la(s) causa(s) de un resultado mucho más de lo que el sentido común -que define las circunstancias normales del contexto sobre la base de exigencias normativas mucho más reducidas- estaría dispuesto a seleccionar como tal. Las dificultades del utilitarismo en este terreno no derivan por tanto de sus rasgos genéricos, sino de lo que constituye su diferencia específica: no de su estructura consecuencialista, sino de su concreta concepción de lo bueno.

Otras veces -por ejemplo, con ocasión del debate acerca del alcance de nuestros deberes positivos generales- se han presentado teorías morales consecuencialistas que incurrían en planteamientos 
circulares $^{38}$ (la tercera de las posibilidades insatisfactorias que enumera Nino). Pero tengo para mí que lo que propiciaba su circularidad no era lo que pudieran tener de consecuencialistas, sino la incorporación del tipo de error que en un contexto diferente (la discusión jurídica relativa a la responsabilidad por daños) Hart y Honoré han denominado «maximalismo causal», esto es, la concepción según la cual «la causación de un daño es condición necesaria y suficiente para la imposición de responsabilidad» ${ }^{39}$. La estrategia argumental que se sigue por quienes sostienen este punto de vista es a grandes rasgos la siguiente: se parte de la idea de que quien causa un daño mediante su actuar positivo es moralmente responsable del mismo (salvo que concurran circunstancias especiales susceptibles de ser alegadas como excusa), presentándola como intuitivamente correcta y no necesitada de mayor justificación; se añade a continuación que cuando todas las demás características del caso son equivalentes no hay ninguna diferencia moralmente relevante entre hacer algo y no impedir que suceda; y a partir de ahí se concluye que somos moralmente responsables de cualquier daño que pudiéramos haber evitado, lo que supuestamente equivaldría a postular un criterio de responsabilidad negativa tan exigente como el del utilitarismo de actos.

Ahora bien, sin duda algo anda mal en un argumento que conduce a una solución tan controvertida a partir de premisas aparentemente tan débiles y difíciles de discutir. La falacia consiste en lo siguiente: o bien los términos que aparecen en las premisas no tienen ningún contenido normativo, y por consiguiente no pueden servir de apoyo a ninguna clase de propuesta moral sustantiva; o de lo contrario el principio al que se llega

${ }^{38}$ Como muestra, cfr. John Harris, «The MarxistConcepción of Violence», en Philosophy and Public Affairs, 3 (1974), 192-220, y «Williams on Negative Responsability and Integrity», en Philosophical Quarterly, 24 (1974), 267-273.

${ }^{39}$ Cfr. el Prefacio a la 2. ${ }^{a}$ edición de Causation in the Law (Oxford, Clarendon Press, 1985), págs. xxxv y lxxiv-1xxvii. Como exponentes de esta postura, surgida como reacción frente al punto de vista predominante entre los partidarios del análisis económico del derecho, vid. Richard A. Epstein, «Nuisance Law: Corrective Justice and Its Utilitarian Constraints», en Journal of Legal Studies, 8 (1979), 49-102; y John Borgo, «Causal Paradigms in Tort Law», en Journal of Legal Studies, 8 (1979), 419-456. Vid. también, como réplica, Richard A. Posner, «The Concept of Corrective Justice in Recent Theories of Tort Law», en Journal of Legal Studies, 10 (1981), 187-206, especialmente, págs. 193-196. 
como conclusión ya estaba dado por supuesto de manera encubierta en las premisas, incurriendo entonces en circularidad. Si por daño se entiende la frustración de un interés (en sentido muy amplio) de quien lo sufre, entonces no es en absoluto obvio que estemos obligados a realizar cualquier acción causalmente eficaz para evitar un «daño» -en este sentido meramente descriptivo a cualquier otro. Sostener que sí lo estamos es asumir una teoría consecuencialista que incorpora una determinada concepción de lo bueno: pero desde otra concepción de lo bueno distinta puede considerarse que una exigencia tan fuerte socava el valor de la autonomía, de manera que algunos de los «daños» -en sentido descriptivo- que podemos sufrir caerían dentro de una «esfera de riesgo» de la que los demás no estarían obligados a librarnos. Y ello porque la distribución óptima de la autonomía funciona como un criterio delimitador en dos direcciones: marca los límites de lo que se nos puede exigir que hagamos respecto a los demás, y, por ello mismo, también los límites de la protección que de los demás podemos reclamar (la esfera de riesgo de cada uno queda contorneada por las esferas de autonomía de todos los demás). Tenemos entonces que, junto al concepto puramente descriptivo de «daño», podemos manejar también otro de carácter normativo: la frustración de un interés que podemos exigir no sufrir (de manera que si algo es un daño para alguien en sentido descriptivo, pero no en sentido normativo, quien se lo evita no se ha limitado a no dañarle, sino que le ha beneficiado $)^{40}$. Cada concepción de lo bueno integrada en una estructura consecuencialista determina qué cuenta como «daño» en sentido normativo, qué deberes tenemos y por tanto cuáles son las presuposiciones normativas que en contextos atributivos estarán presentes en la selección de la acción u omisión que identifiquemos como la causa. Quienes asumen el «maximalismo causal» pretenden recorrer el camino al revés: parten de la idea de «la causa de un daño» como si su significado fuese palmario y pretenden apoyar en ella una opción moral sustantiva. Y como es obvio sólo pueden conseguirlo si ya la han introducido de antemano

${ }^{40}$ Sobre la distinción entre los sentidos descriptivo y normativo de «dañar», cfr. Joel Feinherg, Harm to Others (The Moral Limits of Criminal Law) (Nueva York, /Oxford, Oxford University Press, 1984), págs. 34-36, 105-108 y 130-150. La distinción, desde luego, no tiene nada de novedosa; recuérdese, por ejemplo, cómo al tratar de la justicia correctiva en el libro V, cap. 4. de la Ética Nicomaquea, Aristóteles apunta que el deber de rectificación se basa no sólo en que alguien ha resultado perjudicado (beblaptai), sino en que ha sido tratado injustamente (adikeitai), es decir, en que ha sufrido un perjuicio que podía exigir no soportar. 
en su comprensión de qué cuenta como «la causa» y qué cuenta como «daño». Pero la circularidad proviene de una forma espuria de argumentar en favor de una determinada concepción de lo bueno, no de un vicio estructural del consecuencialismo.

En suma: aunque algunas teorías morales consecuencialistas pueden tener implicaciones contraintuitivas o incurrir en circularidad, la razón de ello no sería una presunta incapacidad del consecuencialismo en general para manejar satisfactoriamente el concepto de causa, sino algún otro factor cuya presencia dentro de una estructura consecuencialista es meramente contingente.

Pero si ello es así, el consecuencialismo como tal debería ser absuelto de los cargos que Nino formula contra él. Más aún: hay para preguntarse si no serán por contra las morales deontológicas las que, en razón de su estructura, pueden encontrar algunos problemas en relación con la idea de causa.

\section{Causalidad y deontologismo}

i) Suele ser habitual definir las morales deontológicas como aquellas en las que lo correcto no está concebido como una función de lo bueno. El sentido exacto de esa idea, no obstante, puede ser interpretado de diferentes maneras. En algunos casos se sostiene que los conceptos mismos de «un estado de cosas bueno» o de «maximización de lo bueno» carecen de sentido -por ejemplo, porque presuponen la posibilidad de agregar y comparar magnitudes heterogéneas-, de modo que sería simplemente absurdo afirmar que la corrección de una acción depende de la bondad de los estados de cosas que resulten de ella ${ }^{41}$. Pero una moral deontológica no tiene por qué llegar tan lejos.

Puede considerar que las nociones de «un estado de cosas bueno» y de «maximización de lo bueno» no sólo son perfectamente inteligibles, sino incluso indispensables para la articulación de un segmento de la moralidad al que, sin mayor afán de precisión, cabe denominar «benevolencia»: pero siempre a condición de que lo correcto -ese otro segmento de la moralidad al que cuadraría el nombre de «justicia»- se presente no como una variable dependiente de lo bueno, sino al contrario, como un conjunto de límites infranqueables definidos previa e independientemente que precisamente constriñen o enmarcan el espacio en el que es lícito perseguir la maximización de lo bueno.

${ }^{41}$ Cfr. John Finnis, Natural Law and Natural Rights, cit. [supra, en nota 19], págs. 112-113. 
Esa caracterización provisional puede descomponerse en dos niveles, uno que remite al plano último de la fundamentación de la moralidad y otro que alude meramente a la forma en que una teoría moral organiza o estructura su contenido ${ }^{42}$. Cuando se habla de deontologismo en el primero de esos niveles, lo que se trata de subrayar es que lo correcto es previo a lo bueno no sólo en el sentido de que sus demandas son prioritarias, sino también y sobre todo en el sentido más profundo de que los principios de lo correcto no presuponen ninguna concepción particular de lo bueno, ni la adopción de ninguna clase de fines, ya que derivarían de alguna instancia -las exigencias de la racionalidad práctica, la idea de un sujeto trascendental, la capacidad misma de elegir fines... -previa a toda concepción del bien y regulativa respecto a ellas. Pero lo que aquí me interesa no es este nivel de la fundamentación, sino el más superficial de la estructura. En este otro plano se puede calificar a una teoría moral como deontológica atendiendo meramente a la concurrencia en ella de algunos rasgos formales, haciendo abstracción del tipo de fundamentación que invoca para adoptarlos. Desde este punto de vista estructural el principal rasgo diferenciador de las morales deontológicas sería el siguiente: los límites no franqueables en la persecución de lo bueno se presentan como algo de valor intrínseco y que se refiere inmediatamente a acciones, no como componentes de estados de cosas a producir (lo que haría que la acción correcta fuese en cada caso la capaz de producir aquel estado de cosas en el que se diera el menor número posible de transgresiones de aquellos límites). Las morales deontológicas, por consiguiente, califican deónticamente clases de acciones (es decir, «actos genéricos») como incondicionalmente obligatorias o prohibidas, sin que ello dependa en cada caso de un juicio previo acerca del diferente nivel de deseabilidad de distintos estados de cosas (para cuya producción resultaría causalmente eficaz la acción que se enjuicia).

Por otra parte, en una teoría moral con estructura deontológica los límites a la persecución de lo bueno pueden estar concebidos primariamente como un conjunto de deberes (de manera que la idea de que alguien tiene un derecho sólo tendría sentido como reflejo o correlato del deber que pesa sobre otro) o como un conjunto de derechos (que operarían entonces como justificación para la imposición de deberes, la atribución de poderes o

${ }^{42}$ Sobre la distinción entre estos dos sentidos o niveles, cfr. Michael J. Sandel, Liberalism and the Limits of Justice (Cambridge, Cambridge University Press, 1982), págs. 2-3. 
inmunidades, etc.). No creo en modo alguno que la discusión acerca de la prioridad conceptual de los deberes o de los derechos carezca de interés, ya que lo que está en juego en ella es el sentido mismo que haya de atribuirse dentro de una teoría moral a la idea de «tener un derecho» ${ }^{43}$. Pero en este momento no es necesario examinar los posibles méritos y deméritos de cada opción: lo que quiero sostener es que el deontologismo encuentra en la idea de causalidad unas dificultades de las que sólo puede librarse deslizándose hacia el consecuencialismo; y a esa conclusión se llega, si no me equivoco, tanto si consideramos como prius conceptual un conjunto de derechos o un conjunto de deberes.

ii) Consideremos en primer lugar una teoría moral deontológica que asigne prioridad conceptual a los derechos. Lo que una teoría moral de este tipo exige, evidentemente, es que se actúe siempre de manera que ninguno de los derechos que se postulan resulte violado (por «buenas» que pudieran ser las consecuencias de esa violación, incluida la reducción del número total de violaciones del mismo tipo que se producirían en caso contrario). Los derechos imponen por consiguiente ciertas restricciones infranqueables sobre la conducta de los demás. Pero, ¿qué restricciones exactamente? ¿Qué es lo que los demás deben incondicionalmente hacer o abstenerse de hacer para que los derechos en cuestión no resulten violados? Para determinar con precisión qué acciones u omisiones son violatorias de derechos tenemos que conocer el alcance respectivo de éstos; pero para determinar ese alcance no hay más salida, si estoy en lo cierto, que desarrollar un tipo de razonamiento que acaba resultando similar al de algunas versiones complejas de consecuencialismo que se examinaron anteriormente.

Pensemos, por ejemplo, en cuáles de nuestras omisiones deben considerarse violatorias de los derechos de otros. En principio podría construirse una respuesta de este tipo: si un derecho queda satisfecho desde el punto de vista de su titular («A») cuando a éste se le asegura -o no se le priva de- cierta capacidad o situación (en sentido muy amplio), toda acción de un tercero

${ }^{43}$ Compárese John L. Mackie, «Can There Be a Right-Based Moral Theory?», en Midwest Studies in Philosophy, 3 (1978), 350-359 [ahora en Mackie, Persons and Values, Selected Papers, vol. II, cit. -supra, en nota 18-, págs. 105-119], donde se defiende el papel primario de los derechos dentro de un sistema moral, con Joseph Raz, The Morality of Freedom (Oxford, Clarendon Press, 1986), cap. VIII [«Right-Based Moralities», págs. 193-216], donde se discuten una serie de dificultades de ese punto de vista. 
(«B») causalmente eficaz para colocar al titular en esa situación cuando no estaba en ella o para evitar que la perdiera debe considerarse moralmente obligatoria (y su omisión, como una violación del derecho en cuestión). Pero una moral deontológica no puede proceder de esa manera. La primera objeción radica, simplemente, en que la calificación deóntica de la omisión también tiene que tomar en cuenta los derechos de B: A sólo tiene derecho a que B actúe si B no tiene a su vez derecho a abstenerse de actuar (el alcance del derecho de cada uno marca el límite del derecho del otro). Esta primera objeción podría salvarse refinando la respuesta que se acaba de ofrecer: se puede afirmar, por ejemplo, que de lo que se trata es de asegurar una cierta distribución para todos de esas capacidades o situaciones, de manera que B habría de hacer todo lo que fuese causalmente eficaz para que A consiga o no pierda las que le corresponden según dicha distribución y que además no suponga el menoscabo de las que le corresponden a él mismo (y viceversa). Me parece que en algunos textos anteriores -si es que no los interpreto abusivamente- Nino ha sostenido una posición de este tipo al ofrecer una solución a la aparente circularidad que lúcidamente advierte que podría producirse entre los principios de autonomía e inviolabilidad de la persona (circularidad que nos impediría fijar el alcance de los derechos), y que consistiría en «maximizar la autonomía de cada individuo por separado en la medida en que ello no implique poner en situación de menor autonomía comparativa a otros individuos», es decir, en «una directiva de expandir siempre la autonomía de aquellos cuya capacidad para elegir y materializar planes de vida esté más restringida ${ }^{44}$.

Pero me parece que ni aun así se escapa a una segunda y más seria objeción: que razonando en esos términos la presunta moral deontológica se ha transmutado inadvertidamente en una forma de consecuencialismo, ya que no ha hecho otra cosa que partir de la valoración previa de estados de cosas y calificar luego deónticamente las acciones a la vista de su eficacia causal para producir dichos estados. Los derechos no han determinado directamente los juicios relativos a las acciones -como se supone que ha de ocurrir en una estructura deontológica-, sino que su satisfacción (la de todos en su alcance respectivo, que no otra cosa significa hablar de una distribución equitativa de la autonomía)

${ }^{44}$ C. S. Nino, Ética y Derechos Humanos, cit. [supra, en nota 4], pág. 212; cfr. también su artículo «Liberty, Equality and Causality», en Rechtstheorie, 15 (1984), 23-38, sec. 5. 
se ha incorporado en primer lugar a la valoración de estados de cosas y ha determinado después la calificación deóntica de las acciones a la vista de su eficacia productora o mantenedora de dichos estados. Cuando los derechos son considerados como capacidades, posiciones o situaciones de los individuos que se consideran valiosas por el control que les confieren sobre importantes aspectos de sus vidas, y a partir de ahí se identifican las acciones u omisiones obligatorias o prohibidas como aquellas causalmente eficaces para asegurar un estado de cosas en el que se dé cierta distribución de esas capacidades o situaciones (con prioridad lexicográfica sobre cualquier otro factor determinante de su bondad), el esquema resultante coincide con lo que anteriormente, siguiendo a Scanlon y a Sen, denominé «sistema de derechos como objetivos» (que no es sino una forma de consecuencialismo, aunque, eso sí, todo lo compleja o refinada que se quiera y desde luego bien distinta del utilitarismo $)^{45}$.

Quizá se pueda replicar que una moral deontológica no tiene por qué proceder de esa manera. Más aún, que no es en absoluto, así como procede, y que por tanto no ha de verse abocada al resultado al que artificialmente yo la habría conducido. Que lo distintivo de las morales deontológicas es precisamente el calificar ciertas acciones genéricas (act-type) como incondicionalmente obligatorias o prohibidas al margen de cuáles sean sus consecuencias, de manera que cada acción individual (act-token) toma su calificación deóntica de la de la acción genérica de la que pueda ser descrita como caso -lo que, dicho sea de pasada, puede generar arduos problemas en forma de conflictos de deberes cuando pueda ser descrita como caso de diferentes acciones genéricas con calificaciones deónticas incompatibles-, no en función de su eficacia causal para mantener o producir estados de cosas en los que concurran determinadas características. Según el criterio kantiano, por ejemplo, las consecuencias buenas o malas de una acción debida no pueden ser imputadas al sujeto, aunque sí las malas consecuencias de una acción ilícita ${ }^{46}$ : y ello

${ }^{45}$ Esta conclusión podría rechazarse si, como Rawls -cfr. supra, nota 17-, se entiende que al prescindir del aditivismo se sale fuera del marco consecuencialista. Me atrevería a conjeturar que eso es lo que está presuponiendo Nino: cfr. su examen del «liberalismo agregativo» y el «liberalismo igualitario» en Ética y Derechos Humanos, cit. págs. 209-214. Para una afirmación tajante de la diferencia entre un «sistema de derechos como objetivos» y el genuino deontologismo, vid. Nozick, Anarchy, State and Utopia, cit. (supra, nota 7), págs. 28-30 [trad. cast., págs. 40-42].

${ }^{46}$ «Die guten oder schlimmen Folgen einer schuldigen Handlung -imgleichen die Folgen der Unterlassung einer verdienstlichen- Können dem Subject 
implica, sin duda, que la calificación deóntica de la acción es previa a la toma en consideración de sus consecuencias. Ahora bien, al empezar a reflexionar de esta manera la prioridad conceptual en el sistema bascula desde los derechos hacia los deberes: porque si los derechos no son vistos como capacidades o situaciones que se han de asegurar (y que justifican la exigencia en cada caso de las acciones individuales causalmente eficaces para ese aseguramiento), sino que se considera que quedan satisfechos meramente en la medida en que los demás cumplan un conjunto tasado de deberes (es decir, realicen o se abstengan de realizar ciertas acciones genéricas), entonces son éstos los que definen el contenido de aquéllos.

iii) Consideremos por tanto una moral deontologica que asigne prioridad conceptual a los deberes, es decir, que califique directamente ciertas clases de acciones como incondicionalmente obligatorias o prohibidas (y en la que los derechos, por consiguiente, no sean más que el correlato de esos deberes). Hay desde luego muchas formas posibles de describir acciones. Una de ellas -de la que por cierto pueden encontrarse ejemplos en todos los sistemas morales más conocidos que hacen suya una estructura de este tipo- es la que las describe como acciones de resultado. «Matar», pongamos por caso, es una acción de resultado. Supongamos una moral deontologica que incluye la prohibición incondicionada de «matar» (o de «matar al inocente», o de «matar no concurriendo las circunstancias $\mathrm{C}_{1}$, $\left.\mathrm{C}_{2}, \ldots, \mathrm{C}_{\mathrm{N}} \gg\right)$. El problema, cuando se prohíbe una acción genérica descrita como acción de resultado, consiste en determinar qué acciones u omisiones pueden ser calificadas como «caso» de esa acción genérica: porque esa calificación exige que se las pueda

nicht zugerechnet werden (modus imputalionis tollens). Die guten Folgen einer verdienstlichen -imgleichen die schlimmen Folgen einer unrechtmäßigen Handlung- können dem Subject zugerechnet werden (modus imputationis ponens)»; Metaphisik der Sitten, Einleitung, en Werke, Akad., vol. VI, pág. 228 [trad. cast. de Felipe González Vicén, Introducción a la Teoría del Derecho (Madrid, C.E.C., La ed. 1954, reimp. 1978), pág. 75: «Las consecuencias buenas o malas de una acción debida, así como las consecuencias de la omisión de una acción meritoria, no pueden ser imputadas al sujeto (modus imputationis tollens). Las buenas consecuencias de una acción meritorias, así como las malas consecuencias de una acción ilícita, pueden ser imputadas al sujeto (modus imputationis ponens)»]. En este sentido similar, escribe la filósofa católica Anscombe: «[...] yo sostendría que un hombre es responsable de las malas consecuencias de sus malas acciones, pero no contrae mérito alguno por las buenas; y a la inversa, que no es responsable de las malas consecuencias de las buenas acciones»; cfr. «Modern Moral Philosophy», cit. [supra, en nota 5], págs. 35-36. 
identificar como la causa del resultado en cuestión. y si no me equivoco una moral con estructura deontologica encuentra en este punto un problema de envergadura.

En el consecuencialismo la calificación deóntica de las acciones precede a los juicios de imputación (que seleccionan una acción u omisión como la causa de un estado de cosas, que se presenta entonces como su resultado). Pero en el caso que ahora estoy considerando es el juicio de imputación el que precede a la calificación deóntica. Una acción u omisión puede ser descrita como un caso de «matar» (y por lo tanto ser calificada como prohibida) si cabe identificarla como la causa de la muerte de alguien, no meramente cuando se cuenta entre las condiciones necesarias -positivas o negativas- de ese resultado: pero lo que eso implica es que -salvo que la acción u omisión en cuestión pueda ser considerada además como caso de otra acción genérica obligatoria o prohibida que el sistema no describa como acción de resultado- el juicio de imputación es un prius conceptual respecto a la calificación deóntica de las acciones u omisiones. Y cuando la prioridad lógica se da en ese sentido, y no en el inverso, el problema radica en determinar de dónde surgen las presuposiciones normativas que identifican el «campo causal» o «condiciones normales del contexto» por referencia a las cuales se efectúa la selección de la causa, es decir, del factor que «marca la diferencia». Si provienen de la moral positiva -i.e., si se selecciona como la causa sólo lo que el «sentido común» identifica como tal-, entonces la moral crítica con estructura deontológica que estamos considerando se convierte en esclava de aquélla. Si provienen del propio deber de abstenerse de matar que la moral crítica establece, se incurre en circularidad.

Podría pensarse que provienen de otros deberes diferentes que la propia moral (crítica) deontológica establece, como por ejemplo de un deber de asistencia o ayuda mutua (de manera que una omisión podría ser vista como la causa de la muerte, es decir, como un caso de «matar», cuando lo omitido fuese la acción

salvadora que prescribe la moral en cuestión). Pero el problema radica en precisar la extensión de este nuevo deber: y no veo fácil determinarla si no es desembocando en una directiva de realizar las acciones causalmente eficaces para asegurar un estado de cosas en el que se dé una determinada distribución de ciertas capacidades o situaciones (con lo que las presuposiciones normativas incorporadas a la delimitación del campo causal provendrían en última instancia de un principio consecuencialista).

iv) La única forma de escapar a esta encerrona, según creo, 
pasaría por tomar un rumbo completamente distinto. Cabría pensar que lo que identifica a una acción u omisión como caso de «matar» (o de cualquier otra acción de resultado genérica) no es tanto que pueda ser vista como la causa de ese resultado, con las dificultades que ello supone, sino más bien la intención del agente, puesta de manifiesto en su actuar (positivo o negativo). Tomando en préstamo términos corrientes en la dogmática jurídico-penal, lo decisivo sería entonces el «desvalor de acción», no el «desvalor de resultado». Por consiguiente las acciones $u$ omisiones del agente habrían de ser individualizadas e identificadas con arreglo al modo en que él mismo las caracteriza en el razonamiento práctico que precede y guía su actuar.

Ahora bien, esta propuesta no está exenta de dificultades, y para hacerles frente no parece haber otro recurso que acudir a las distinciones establecidas por la vieja doctrina del doble efecto. Si, como dice Tomás de Aquino, «los actos morales reciben su especie de lo que está en la intención y no de lo que es ajeno a ella» ${ }^{47}$, una acción u omisión podrá ser calificada como caso de cierta acción genérica de resultado (p. ej., de «matar») cuando el agente busque dicho resultado como fin o como medio para otro fin, pero no cuando -sin buscarlo como fin ni como medio meramente prevea, incluso con certidumbre plena, que su acción producirá ese resultado (o que la acción que omite lo evitaría). Esa distinción permite justificar por qué no cabe transgredir una prohibición incondicional ni siquiera para evitar un mal mayor o un número mayor de transgresiones del mismo tipo (porque la transgresión sería imputable al sujeto al quererla como medio para otro fin, mientras que el mal mayor no lo será al ser una consecuencia prevista pero no querida), o por qué en determinadas circunstancias es lícita la realización de acciones causalmente eficaces para producir el resultado prohibido (si el sujeto las realiza previendo ese resultado pero buscando un fin distinto).

Lo que sucede es que la doctrina del doble efecto, como se ha señalado con frecuencia, tiene una base muy controvertible ${ }^{48}$. Cuando el agente forma su intención no puede ignorar sin más las leyes causales que rigen el mundo, no puede desentenderse de la dimensión instrumental de su actuar, como si no tuviera nada

${ }^{47}$ T. Aquino, Summa Theologiae, $\mathrm{II}^{\mathrm{a}}-\mathrm{II}^{\mathrm{a}}$, q. 64, a,7.

${ }^{48}$ Vid., p. ej., H. L. A. Hart, «Intention and Punishment», en Oxford Review, 4 (1967) [ahora en H. L. A. Hart, Punishment and Responsability, Essays in the Philosophy of Law (Oxford, Clarendon Press, 1968), págs. 113-135, por donde se cita], págs. 122-125; y J. L. Mackie, Ethics: Inventing Right and Wrong, cit. [supra, en nota 7], pág. 166. 
que ver con él lo que prevé como consecuencia inevitable de su acción, y resulta como mínimo discutible qué debe entenderse que queda abarcado por su «intención» ${ }^{49}$. Por otra parte la distinción entre lo querido como un medio y lo meramente previsto como una consecuencia necesaria, aunque puede parecer clara desde un punto de vista formal, en el fondo depende muchas veces de la aplicación de distintas descripciones verbales a casos entre los que no siempre es fácil detectar diferencias relevantes que justifiquen una distinta calidad moral, con lo que resulta demasiado artificial como para considerarla un criterio seguro dentro de una teoría moral viable. Ahora bien, por más discutible que sea la doctrina del doble efecto (y a mi juicio lo es en muy alto grado), difícilmente podría funcionar sin ella una moral deontológica que califica como incondicionalmente obligatorias o prohibidas ciertas acciones de resultado. Por una razón muy sencilla: de no dar relevancia a las distinciones en las que insiste la tesis del doble efecto, habría casos en los que cualquiera de las acciones posibles para el agente (incluida la absoluta pasividad) podría ser calificada como transgresión de una prohibición incondicional, y en los que por consiguiente la teoría en cuestión quedaría irremisiblemente bloqueada.

v) En conclusión: una moral deontológica deriva inadvertidamente hacia una estructura consecuencialista cuando los derechos se consideran como capacidades o situaciones de las que se ha de asegurar una determinada distribución; cuando por el contrario parte de la postulación de un catálogo de deberes, es decir, de acciones genéricas calificadas incondicionalmente como obligatorias o prohibidas, o bien no describe ninguna de ellas como acción de resultado -algo que hacen todos los ejemplos más conocidos de morales deontológicas-, o de lo contrario, alternativamente, a) tropieza con todos los problemas que dimanan de atribuir a los juicios de imputación prioridad lógica sobre la calificación deóntica de las acciones (dependencia de la moral positiva; o de un principio consecuencialista; o circularidad); o b) su viabilidad depende enteramente de la discutible doctrina del doble efecto.

${ }^{49}$ Sobre este punto, vid. Gilbert Harmann, «Rational Action and the Extent of Intentions», en Social Theory and Practice, 9 (1983), 123-141. 